\title{
Mutational analysis of epidermal and hyperproliferative type I keratins in mild and moderate psoriasis vulgaris patients: a possible role in the pathogenesis of psoriasis along with disease severity
}

\author{
Tamilselvi Elango ${ }^{1,5^{*}+}$, Jingying Sun ${ }^{1}$, Caihong Zhu' ${ }^{1}$, Fusheng Zhou' ${ }^{1}$, Yaohua Zhang ${ }^{4}$, Liangdan Sun ${ }^{1,2,3}$,
} Sen Yang ${ }^{1,2,3}$ and Xuejun Zhang ${ }^{1,2,3,4,5^{*}+}$

\begin{abstract}
Background: Mutations in keratin proteins have been vastly associated with a wide array of genodermatoses; however, mutations of keratins in psoriasis have not been fully investigated. The main aim of the current research was to identify the mutation in $\mathrm{K} 14, \mathrm{~K} 10, \mathrm{~K} 16$, and $\mathrm{K} 17$ genes in two stages of psoriasis patients.

Methods: Ninety-six psoriatic skin biopsies were collected. mRNA transcript of K14, K10, K16, and K17 was prepared, amplified, and sequenced. Sanger sequences of all keratins were further validated for mutational analysis using Mutation Surveyor and Alamut Visual. Then, in silico analysis of protein stability and protein and gene expression of all keratins was performed and validated.

Results: Out of 44 mutations, about $75 \%$ of keratins are highly pathogenic and deleterious. Remaining $25 \%$ mutations are less pathogenic and tolerated in nature. In these 33 deleterious mutations were immensely found to decrease keratin protein stability. We also found a correlation between keratin and Psoriasis Area and Severity Index score which added that alteration in keratin gene in skin causes severity of psoriasis.

Conclusions: We strongly concluded that acanthosis and abnormal terminal differentiation was mainly due to the mutation in epidermal keratins. In turn, disease severity and relapsing of psoriasis are mainly due to the mutation of hyperproliferative keratins. These novel keratin mutations in psoriatic epidermis might be one of the causative factors for psoriasis.
\end{abstract}

Keywords: Epidermal keratins, Hyperproliferative keratins, Psoriasis, Mutation, Sanger sequence, Immunofluorescence

\section{Background}

Keratinocytes play a special role in sensing epidermal barrier and regulating immune homeostasis [1]. Its functions mainly depend on structural proteins including keratins $[2,3]$. Keratins are the main intermediate filament cytoskeleton in all epithelia [4]. In normal skin, basal cells express two keratins, K5 and K14, whereas suprabasal cells express

\footnotetext{
*Correspondence: tami24684@gmail.com; ayzxj@vip.sina.com

${ }^{\dagger}$ Equal contributors

${ }^{1}$ Institute and Department of Dermatology, The First Affiliated Hospital,

Anhui Medical University, Hefei, China

Full list of author information is available at the end of the article
}

differentiation-related keratins $\mathrm{K} 1$ and K10. These pairs act as a flexible scaffold enabling cells to resist physical stress and also play different cellular functions including protection from apoptosis and regulation of epithelial organization $[5,6]$. Consequently, defects in intermediate filaments (Ifs) can lead to cell fragility and are linked to a wide array of genodermatoses and cancers $[7,8]$.

Psoriasis is a genetically determined chronic inflammatory skin disease characterized by acanthosis, abnormal keratinization, and inflammatory cell infiltrates [9]. In psoriatic lesions, terminal differentiation of keratinocytes is incomplete, which leads to preferential activation and 
proliferation of cells that do not mature properly. These changes are mainly associated with altered expression of keratin in psoriasis [10]. In psoriasis, the changes in keratin expression include a reduction in $\mathrm{K} 1$ and $\mathrm{K} 10$ and the induction of hyperproliferation-associated keratins K6, K16, and K17 [11-13]. Furthermore, the expression levels of $\mathrm{K} 5$ and $\mathrm{K} 14$ in the basal cell layer are also altered in the psoriatic epidermis. The hyperproliferation in psoriasis seemed to result from an increase in the number of transit amplifying cells, following depletion of the stem cell compartment $[14,15]$. As a whole, these changes suggest that each keratin pair provides specific functional requirements to epidermal keratinocytes.

Over $90 \%$ of pathogenic mutations in keratinopathies are missense mutations with a small number of small inframe insertions vs. deletion mutations and a few intronic splice site defects leading to larger in-frame deletions. Various cutaneous disorders are identified with mutated keratin proteins namely epidermolysis bullosa simplex (EBS) (K5, K14), ichthyosis (K1, K2, and K10), palmoplantar keratoderma (K9), type I pachyonychia congenita (PC) (K6a and K16), seven type II pachyonychia congenita (K6b and K17), and monilethrix (K81, K83, and K86). [16-18]. In most of these conditions, the associated pathology results from fragile keratinocytes expressing the mutated keratin protein.

Since genome-wide association studies (GWAS), connecting the psoriasis to the late cornified envelope gene cluster has specified that epidermal abnormalities along with hyperproliferative keratin pattern play a major role in the pathogenesis of psoriasis $[19,20]$. The main aim of this study is to identify the mutation of keratin in two stages of psoriasis, which mainly causes hyperproliferation along with defects in the cornification process. We speculated that mutation in K14 and K10 might serve as an important mechanism that affects keratinocyte proliferation in all stages of psoriasis, and also, mutation in hyperproliferative keratin $\mathrm{K} 16$ and $\mathrm{K} 17$ might be the foremost cause for the incurability and exacerbation of this disease. To verify our hypotheses, we examined Sanger sequence of the CDS region of all these keratins in both stages. For mutational analysis, we performed a computational analysis of all these keratins in both stages of psoriasis by using Mutation Surveyor and Alamut Visual software. In addition, effects of these mutations on protein stability were predicted by using in silico prediction tools. According to our result, the predicted deleterious mutations were mainly clustered in the rod domain on the keratin protein, which is crucial for keratin function. Most of the deleterious mutations were predicted to decrease protein stability which might cause the changes in protein expression of these keratins. All these changes might trigger or exacerbate psoriasis.

\section{Materials and methods \\ Patients' details}

Patients with psoriasis vulgaris $(n=96)$ who visited the Institute of Dermatology, Anhui Medical University (AHMU), between 2015 and 2017 were recruited in this study. The age of all patients ranged from 16 to 71 years (mean \pm SD, $37.97 \pm 14.03$ years). In this study, based on body surface area involvement, we have categorized patients into two, (i) mild psoriasis patients $(n=48)$ and (ii) moderate psoriasis patients $(n=48)$. Severity of plaque psoriasis was graded into mild and moderate to severe disease. Mild disease was defined as body surface area $(\mathrm{BSA}) \leq 10$, Psoriasis Area and Severity Index $(\mathrm{PASI}) \leq 10$, and dermatology life quality index (DLQI) $\leq 10$ and moderate to severe psoriasis as BSA $>10$ or PASI $>10$ and DLQI $>10$ [21]. Patients were included in the study based on the following criteria: (i) at least one well-demarcated, erythematous, scaly lesion verified by at least two dermatologists; (ii) each lesion tissue was confirmed by clinical histopathology; (iii) no systematic anti-psoriatic treatment 2 weeks before skin biopsy; and (iv) no topical anti-psoriatic treatments for 1 week prior to biopsy. Informed consent was obtained from all individuals, under an AHMU-approved protocol. The study was approved by the institutional ethical committee and conducted according to the Declaration of Helsinki principles.

\section{Collection of tissue samples}

In all patients, $10 \mathrm{~mm}$ of lesional and nonlesional skin biopsies were taken after local anesthesia, lidocaine hydrochloride, and adrenaline bitartrate IP were given intradermally. Nonlesional skin biopsy served as control. Biopsies of psoriatic lesional skin were taken within a lesion, $1 \mathrm{~cm}$ from the edge of the plaque border. Biopsies of nonlesional skin were taken $2 \mathrm{~cm}$ beyond the plaque border. Skin biopsies were immediately frozen in liquid nitrogen.

\section{Histology analysis}

Formalin-fixed skin biopsy was embedded in paraffin and processed routinely. Hematoxylin-eosin staining was used to examine the histological changes in mild and moderate psoriatic skin.

\section{RNA isolation and qRT-PCR}

RNA from both skin tissues were isolated by TRIZOL Method, and RT-PCR was conducted using the HighCapacity cDNA Reverse Transcription Kits (Applied Biosystems, USA) according to the manufacturer's protocol. Taqman Master Mix (Applied Biosystems, Bedford, MA) was used with Taqman probes. Real-time quantitative PCR was performed with the ABI PRISM7700 Sequence Detection System. All expression values were normalized against 
GAPDH. Relative mRNA expression levels of all examined genes were measured using the comparative $2^{-\Delta \Delta C T}$ [22]. All amplifications were done three times in triplicate.

PCR amplification, sequencing, and mutation screening cDNA prepared from mild and moderate psoriatic RNA samples were amplified using a polymerase chain reaction (PCR). The primers were designed from the CDS region of all these keratins (Table 1). PCR reaction was performed using Biorad Thermal Cycler. The PCR conditions were as given in Table 1. Amplified PCR products were electrophoresed through a $1.5 \%$ agarose gel, to control the quality of fragments. Sanger sequencing reactions were performed on the purified PCR fragments using a BigDye ${ }^{\ominus}$ Terminator v3.1 Cycle Sequencing Kit (Applied Biosystems, USA) with the same primers as for the PCRs, forward and reverse primers in separate experiments. All genes were sequenced from both directions. Reactions were processed on the ABI3730xl instrument. Sequence reads were analyzed using Applied Biosystems. Sequence reads were aligned to human genome by using Bioedit software.

Mutation Surveyor is a useful in silico tool developed by SoftGenetics that assists the detection of sequence variations within Sanger sequencing traces. This tool can process up to 400 lanes of data at a time with high accuracy and sensitivity. It can effectively detect SNPs and mutation in their homozygous or heterozygous states as well as mosaicism [23]. In this study, we did sequence analysis and pathogenic variant identification by using Mutation Surveyor DNA variant analysis software (SoftGenetics, USA). For prediction of the mutation's pathogenicity, Alamut Visual software (Interactive Biosoftware, France) was used [24]. Studies have shown that Alamut Visual is the original decision-support software application, used by leading genetic clinicians and researchers around the world. This software was used for alignment, conservation, SIFT/PolyPhen dbSNP, and Exome Sequencing Project data collection to evaluate the variant in its surrounding genomic context [25, 26]. All variants were further annotated with the Exome Aggregation Consortium (ExAC) [27].

\section{Prediction of deleterious mutations}

Six best performing tools were combined into a consensus classifier PredictSNP1.0, which gives significantly improved prediction performance and at the same time returned results for all mutations, confirming that consensus prediction represents an accurate and robust alternative to the predictions delivered by individual tools. Also, this is a user-friendly web interface for all researchers and clinician which enables an easy access to all eight prediction tools, the consensus classifier PredictSNP, and annotations from the Protein Mutant Database and the UniProt database. Based on the above details, we used PredictSNP1.0 (http://loschmidt.chemi.muni.cz/predictsnp1), classifier webserver, to predict the effects of mutations on protein function [28]. PredictSNP1.0 runs and integrates MAPP, nsSNPAnalyzer, PANTHER, PhD-SNP, Polyphen-1, Polyphen-2, SIFT, and SNAP to predict disease-related amino acid mutations. The four tools use machine-learning methods; nsSNPAnalyzer uses random forest, PhD-SNP uses support vector machines, PolyPhen-2 uses Naive Bayes, and SNAP uses neural network. SIFT, MAPP, and PANTHER consider alignment score information, and PolyPhen-1 uses an expert set of empirical rules to predict possible impact of amino acid substitutions. PredictSNP1.0 displays the confidence scores generated by each tool and a consensus prediction as percentages by using their observed accuracy values to ease comparisons [29].

Table 1 Primer sequences and reaction conditions used for PCR

\begin{tabular}{|c|c|c|c|c|}
\hline S. no. & Primer & Sequences (5'-3') & Length (bp) & Reaction conditions \\
\hline \multirow[t]{2}{*}{1} & K14 F & GTGGGCAGTGAGAAGGTGAC & \multirow[t]{2}{*}{966} & \multirow{2}{*}{$\begin{array}{l}\text { Denaturation, } 30 \mathrm{~s} \text { at } 94^{\circ} \mathrm{C} \\
\text { Annealing, } 45 \mathrm{~s} \text { at } 59^{\circ} \mathrm{C} \\
\text { Extension, } 60 \mathrm{~s} \text { at } 72{ }^{\circ} \mathrm{C} \\
\text { No. of cycles, } 35\end{array}$} \\
\hline & K14 R & AGAGGAGAACTGGGAGGAGG & & \\
\hline \multirow[t]{2}{*}{2} & K10 F & GGCTCATCAGGTGGCTAT & \multirow[t]{2}{*}{812} & \multirow{2}{*}{$\begin{array}{l}\text { Denaturation, } 30 \mathrm{~s} \text { at } 94^{\circ} \mathrm{C} \\
\text { Annealing, } 45 \mathrm{~s} \text { at } 58^{\circ} \mathrm{C} \\
\text { Extension, } 60 \mathrm{~s} \text { at } 72{ }^{\circ} \mathrm{C} \\
\text { No. of cycles, } 35\end{array}$} \\
\hline & K10 R & CAGGCTTCAGCATCTITG & & \\
\hline \multirow[t]{2}{*}{3} & K16 F & GTGAAGATCCGTGACTGG & \multirow[t]{2}{*}{856} & \multirow{2}{*}{$\begin{array}{l}\text { Denaturation, } 30 \mathrm{~s} \text { at } 94{ }^{\circ} \mathrm{C} \\
\text { Annealing, } 45 \mathrm{~s} \text { at } 56^{\circ} \mathrm{C} \\
\text { Extension, } 60 \mathrm{~s} \text { at } 72{ }^{\circ} \mathrm{C} \\
\text { No. of cycles, } 35\end{array}$} \\
\hline & K16 R & TGCTGGGAGGAAAGGTGG & & \\
\hline \multirow[t]{2}{*}{4} & $\mathrm{~K} 17 \mathrm{~F}$ & CTTCCGCACCAAGTTTGA & \multirow[t]{2}{*}{753} & \multirow{2}{*}{$\begin{array}{l}\text { Denaturation, } 30 \mathrm{~s} \text { at } 94^{\circ} \mathrm{C} \\
\text { Annealing, } 45 \mathrm{~s} \text { at } 55^{\circ} \mathrm{C} \\
\text { Extension, } 60 \mathrm{~s} \text { at } 72{ }^{\circ} \mathrm{C} \\
\text { No. of cycles, } 35\end{array}$} \\
\hline & K17 R & TTGCCATCCTGGACCTCT & & \\
\hline
\end{tabular}


The effects of predicted deleterious mutations on protein stability

The effect of deleterious missense amino acid substitutions on K14, K10, K16, and K17 protein stability was analyzed with MUpro (http://mupro.proteomics.ics.uci.edu) [30] and I-Mutant2.0 (http://folding.biofold.org/i-mutant/ i-mutant2.0.html) [31]. MUpro uses support vector machine (SVM) and neural network to predict the effect of amino acid changes on protein stability and calculates a score between -1 and 1 as the confidence of prediction. A confidence score $<0$ indicates the mutation decreases the protein stability, while a confidence score $>0$ means the mutation increases the protein stability. I-Mutant 2.0 uses SVM to predict protein stability alterations upon mutations and provides the predicted free energy change value (DDG) and the sign of the prediction as increase or decrease. DDG is calculated as unfolding Gibbs free energy value (mutated protein) - unfolding Gibbs free energy value (wild-type protein) in $\mathrm{Kcal} / \mathrm{mole}$. DDG $>0$ means increased protein stability, and DDG $<0$ means decreased protein stability.

\section{Visualization of predicted deleterious mutations on 3D keratin structure}

The location of predicted deleterious mutations was detected by STRUM (http://zhanglab.ccmb.med.umich. edu/STRUM/), which constructs 3D models according to the iterative threading assembly refinement (I-TASSER) simulation [32].

\section{Western blot analysis}

Western blot was performed as previously described [33] using primary antibodies as follows: K14, K10, K16, and K17 and $\beta$-actin (Thermo-scientific, USA). Band intensity was analyzed using ImageJ software (http://rsb. info.nih.gov/ij/).

\section{Immunofluorescence and confocal microscopy}

Immunofluorescence assay was performed as described previously [34]. Skin biopsies were obtained from the lesional and nonlesional skin of each patient (control samples). Tissues were sectioned $(4 \mu \mathrm{m})$ and stained with rabbit monoclonal anti-cytokeratin 14 and mouse monoclonal anti-cytokeratin10, 16, and 17 (Thermo-scientific, USA). An appropriate Alexa Fluor 488-conjugated anti-rabbit IgG and anti-mouse IgG (Thermo-scientific, USA) and DAPI staining of nuclei were used. The images were examined by the pathologist using an Olympus-Ix Microscope and merged using Image J Software.

\section{Statistical analysis}

Results were expressed as mean $\pm \mathrm{SD}$. Data were analyzed using SPSS 16.0 software. Nonlesional and lesional skin biopsy samples were compared by Student's $T$ test. Spearman's coefficient was used to identify correlations between keratins and PASI score. $P<0.05$ was considered to be significant.

\section{Results}

\section{Baseline analysis of psoriatic lesion}

The histological examination of nonlesional skin tissue shows normal rete ridges with stratum corneum whereas that of mild and moderate lesional skin revealed elongated rete ridges with deregulated stratum corneum (Fig. 1a). Histological analysis was further supported by PASI score. Forty-eight patients with mild psoriasis have a PASI score of $4.06 \pm 2.46$, and the remaining 48 patients with moderate psoriasis have a PASI score of $17.34 \pm 5.64$ (Fig. 1b).

\section{Mutated keratin sequences identified through Sanger sequencing}

Almost in all the keratin mutation and sequence studies, NCBI database is widely used, NM_000526.4 (K14), NM_000421.3 (K10), NM_005557.3 (K16), and NM_ 000422.2 (K17), as publicly available sequence data for healthy population (control). According to the above keratins, nucleotide accession number of these sequences is also retrieved from the Chinese population [35-39]. So, in order to predict the mutation in two stages of psoriasis, we have taken the K14, K10, K16, and K17 coding sequences of healthy population available in NCBI database with accession numbers NM_000526.4 (K14), NM_000421.3 (K10), NM_005557. 3 (K16), and NM_000422.2 (K17), which were further aligned respectively with the Sanger sequences of K14, K10, K16, and K17 obtained in our patients by using BioEdit software (Additional file 1: Figs. S1 and S2). In mild psoriasis patients, we have identified nine and seven missense mutations in K14 and K10, respectively, as well as no missense mutation was found in K16 and K17. However, in moderate psoriasis, we found nine, six, five, and eight mutations of K14, K10, K16, and K17, respectively.

Some of our mutated K14, K10, and K17 sequences were matched to previously reported sequences in other skin disease (Table 2). In order to compare the mutation identified in psoriasis patients with other skin disease patients, we have used the following Clinvar data in the NCBI website (https://www.ncbi. nlm.nih.gov/clinvar/) (Tables 3 and 4). According to the Clinvar data of NM_000526.4 (K14), 11 missense mutations of K14 were found in EBS disease; comparing these mutations with our K14 results, three mutations were found to be identical in both diseases. Likewise, NM_000421.3 (K10) compared with K10 of our patients showed only one identical mutation. Compared with our results, no identical mutation was 

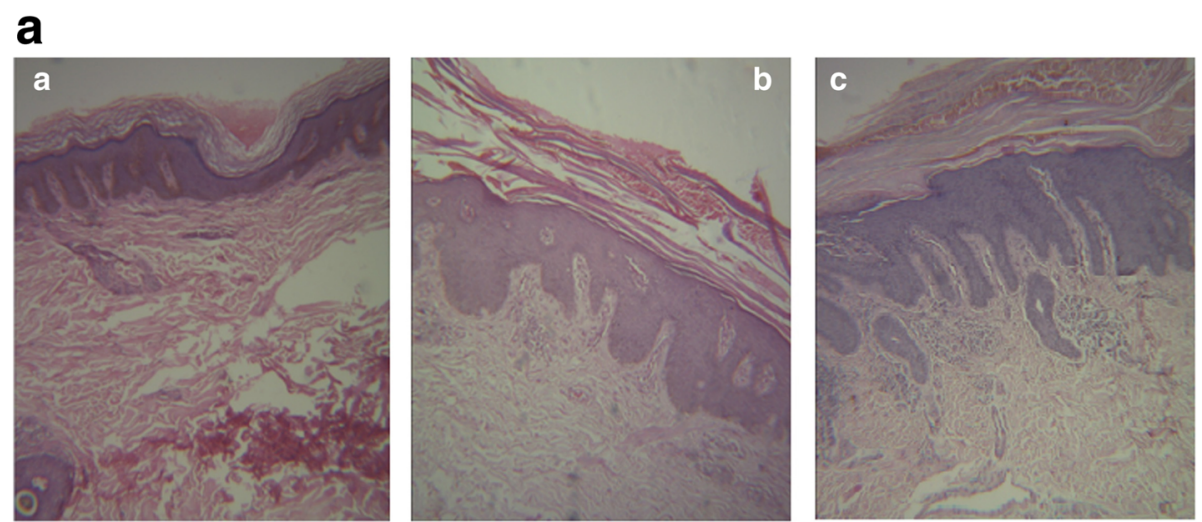

b

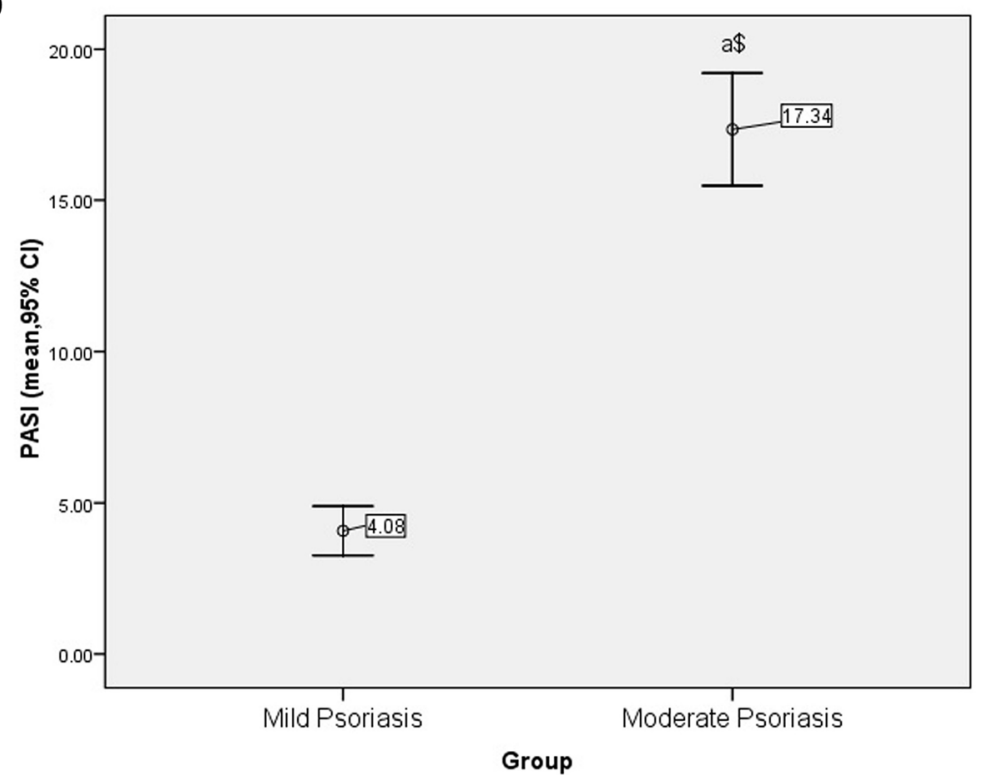

Fig. 1 Histological and clinical examinations of mild and moderate psoriatic skin. a Histological examination of skin biopsy. (A) Photomicrograph of nonlesional skin biopsy. (B), (C) Photomicrograph of mild and moderate psoriasis vulgaris showing Munro microabscess, acanthosis, rete ridge elongation, and acute infiltration of dermis. $\mathbf{b}$ Clinical evidence of mild and moderate psoriatic lesion by PASI score. All values were expressed as mean \pm SD. "a" denotes comparison of PASI score of mild and moderate psoriasis. The dollar sign denotes $P<0.001$

Table 2 Mutated epidermal and hyperproliferative keratin sequences identified in this study consistent with previous reports (clinvar and dbSNP in the NCBI website)

\begin{tabular}{lllll}
\hline S. no. & Gene & Mutation region & Accession number \\
\cline { 3 - 4 } & & Clinvar & dbSNP \\
\hline 1 & Keratin 14 & C442 > T & RCV000056740.1 & rs58378809 \\
2 & & A1234 > T & RCV000056680.1 & rs267607403 \\
3 & & G1237 > A & RCV000056682.1 & rs59780231 \\
4 & & C1246 > T & & rs777067461 \\
5 & Keratin 10 & C520 > A & RCV000056502.1 & \\
6 & Keratin 17 & C986 > T & & rs780535087 \\
\hline
\end{tabular}

found in both keratin 16 and 17. Based on per nucleotide sequence variation, percentage of background mutation rate was calculated. The high background mutation rates of $\mathrm{K} 14$ mutated nucleotide sequences in our patients were $33.3 \% \mathrm{G}>\mathrm{C}$, followed by $22.2 \%$ $\mathrm{A}>\mathrm{T}, 16.6 \% \mathrm{C}>\mathrm{T}, 11.1 \% \mathrm{G}>\mathrm{T}$, and $5.5 \%$ of $\mathrm{C}>\mathrm{A}$, $\mathrm{G}>\mathrm{A}$, and $\mathrm{C}>\mathrm{G}$, whereas EBS disease condition obtained from the NCBI website showed high mutation rate of $36.3 \% \mathrm{G}>\mathrm{A}$. Background mutation rates of psoriasis K10 were as follows: $\mathrm{G}>\mathrm{T}, \mathrm{T}>\mathrm{A}, \mathrm{G}>\mathrm{C}, \mathrm{A}>\mathrm{C}, \mathrm{C}>\mathrm{G}$, and $\mathrm{C}>\mathrm{A}$ with percentages of $30.7,15.3$, and $7.6 \%$. In $\mathrm{EI}$ disease, $\mathrm{A}>\mathrm{C}$ nucleotide $\mathrm{K} 10$ mutation is found to be $23 \%$ followed with $15.3 \%$ of $\mathrm{G}>\mathrm{A}$ and $\mathrm{T}>\mathrm{C}$. The most highest K16 mutated nucleotide found in our study is $40 \%$ of $\mathrm{C}>\mathrm{G}$ whereas $25 \%$ of $\mathrm{A}>\mathrm{T}, \mathrm{C}>\mathrm{T}$, and $\mathrm{G}>\mathrm{T}$ was found in $\mathrm{K} 17$. 
Table 3 Comparison of publicly available mutated keratin 14 and keratin 10 sequence data of various skin disease patients with mutated sequence obtained in our study (psoriasis) from Clinvar NCBI database

\begin{tabular}{|c|c|c|c|c|c|c|c|c|c|c|}
\hline \multirow[t]{2}{*}{ S. no. } & \multirow[t]{2}{*}{ Name } & \multirow[t]{2}{*}{ Gene(s) } & \multirow[t]{2}{*}{ Condition(s) } & \multirow{2}{*}{$\begin{array}{l}\text { Clinical significance } \\
\text { (Last reviewed) }\end{array}$} & \multicolumn{2}{|l|}{ GRCh37 } & \multicolumn{2}{|l|}{ GRCh38 } & \multirow[t]{2}{*}{ Variation ID } & \multirow[t]{2}{*}{ Allele ID(s) } \\
\hline & & & & & Chromosome & Location & Chromosome & Location & & \\
\hline 1 & $\begin{array}{l}\text { NM_000526.4(KRT14): } \\
\text { c.1264G > A (p.Glu422Lys) }\end{array}$ & KRT14 & EBH-DM & $\begin{array}{l}\text { Pathogenic } \\
\text { (Apr 1, 2000) }\end{array}$ & 17 & 39739497 & 17 & 41583245 & 14623 & 29662 \\
\hline 2 & $\begin{array}{l}\text { NM_000526.4(KRT14): } \\
\text { c.1256T > A (p.Leu419GIn) }\end{array}$ & KRT14 & EBH-DM & $\begin{array}{l}\text { Pathogenic } \\
\text { (Apr 1, 2000) }\end{array}$ & 17 & 39739505 & 17 & 41583253 & 14622 & 29661 \\
\hline 3 & $\begin{array}{l}\text { NM_000526.4(KRT14): } \\
\text { c.1243T > C (p.Tyr415His) }\end{array}$ & KRT14 & EBH-DM & $\begin{array}{l}\text { Pathogenic } \\
\text { (Mar 27, 2015) }\end{array}$ & 17 & 39739518 & 17 & 41583266 & 14621 & 29660 \\
\hline 4 & $\begin{array}{l}\text { NM_000526.4(KRT14): } \\
\text { c.1237G > A (p.Ala413Thr) }\end{array}$ & KRT 14 & Not provided & $\begin{array}{l}\text { Pathogenic } \\
\text { (Jul 31, 2012) }\end{array}$ & 17 & 39739524 & 17 & 41583272 & 66319 & 77216 \\
\hline 5 & $\begin{array}{l}\text { NM_000526.4(KRT14): } \\
\text { c.1234A > T (p.lle412Phe) }\end{array}$ & KRT14 & Not provided & $\begin{array}{l}\text { Pathogenic } \\
\text { (Apr 2, 2018) }\end{array}$ & 17 & 39739527 & 17 & 41583275 & 66317 & 77214 \\
\hline 6 & $\begin{array}{l}\text { NM_000526.4(KRT14): } \\
\text { c.1228C > T (p.Gln410Ter) }\end{array}$ & KRT14 & Not provided & $\begin{array}{l}\text { Pathogenic } \\
(\text { Sep 15, 2016) }\end{array}$ & 17 & 39739533 & 17 & 41583281 & 66313 & 77210 \\
\hline 7 & $\begin{array}{l}\text { NM_000526.4(KRT14): } \\
\text { c.1162C > T (p.Arg388Cys) }\end{array}$ & KRT14 & Not provided & $\begin{array}{l}\text { Pathogenic } \\
(\text { Oct 13, 2017) }\end{array}$ & 17 & 39739599 & 17 & 41583347 & 66306 & 77203 \\
\hline 8 & $\begin{array}{l}\text { NM_000526.4(KRT14): } \\
\text { c.1151T > C (p.Leu384Pro) }\end{array}$ & KRT14 & EBS, Koebner type & $\begin{array}{l}\text { Pathogenic } \\
\text { (Nov 22, 1991) }\end{array}$ & 17 & 39739610 & 17 & 41583358 & 14611 & 29650 \\
\hline 9 & $\begin{array}{l}\text { NM_000526.4(KRT14): } \\
\text { c.442C > T (p.Arg148Cys) }\end{array}$ & KRT14 & EBS, Koebner type & $\begin{array}{l}\text { Pathogenic } \\
\text { (Apr 2, 2018) }\end{array}$ & 17 & 39742645 & 17 & 41586393 & 66368 & 77265 \\
\hline 10 & $\begin{array}{l}\text { NM_000526.4(KRT14): } \\
\text { c.374G > A (p.Arg125His) }\end{array}$ & KRT14 & EBH-DM & $\begin{array}{l}\text { Pathogenic } \\
(\text { Oct 30, 2017) }\end{array}$ & 17 & 39742713 & 17 & 41586461 & 14613 & 29652 \\
\hline 11 & $\begin{array}{l}\text { NM_000526.4(KRT14): } \\
\text { c.357G > A (p.Met119lle) }\end{array}$ & KRT14 & $\begin{array}{l}\text { EBS, autosomal } \\
\text { recessive }\end{array}$ & $\begin{array}{l}\text { Pathogenic } \\
\text { (Sep 1, 1997) }\end{array}$ & 17 & 39742730 & 17 & 41586478 & 14620 & 29659 \\
\hline 12 & $\begin{array}{l}\text { NM_000421.3(KRT10): } \\
\text { c.1374-2A >C }\end{array}$ & KRT10 & Not provided & $\begin{array}{l}\text { Pathogenic } \\
\text { (Nov 25, 2015) }\end{array}$ & 17 & 38975415 & 17 & 40819163 & 449615 & 445767 \\
\hline 13 & $\begin{array}{l}\text { NM_000421.3(KRT10): } \\
\text { c.1374-2A > G }\end{array}$ & KRT10 & $\begin{array}{l}\text { El, congenital } \\
\text { reticular }\end{array}$ & $\begin{array}{l}\text { Pathogenic } \\
(\text { Oct 1, 2010) }\end{array}$ & 17 & 38975415 & 17 & 40819163 & 14581 & 29620 \\
\hline 14 & $\begin{array}{l}\text { NM_000421.3(KRT10): } \\
\text { c.1373 + 2T >C }\end{array}$ & KRT10 & Not provided & $\begin{array}{l}\text { Pathogenic } \\
\text { (May 9, 2017) }\end{array}$ & 17 & 38975767 & 17 & 40819515 & 432261 & 426219 \\
\hline 15 & $\begin{array}{l}\text { NM_000421.3(KRT10): } \\
\text { c.1373 + 1G > A }\end{array}$ & KRT10 & $\begin{array}{l}\text { El, congenital } \\
\text { reticular }\end{array}$ & $\begin{array}{l}\text { Pathogenic } \\
\text { (Oct 1, 2010) }\end{array}$ & 17 & 38975768 & 17 & 40819516 & 14582 & 29621 \\
\hline 16 & $\begin{array}{l}\text { NM_000421.3(KRT10): } \\
\text { c.1325T > A (p.Leu442GIn) }\end{array}$ & KRT10 & $\mathrm{BIE}$ & $\begin{array}{l}\text { Pathogenic } \\
\text { (Feb 1, 1994) }\end{array}$ & 17 & 38975817 & 17 & 40819565 & 14575 & 29614 \\
\hline 17 & $\begin{array}{l}\text { NM_000421.3(KRT10): } \\
\text { c.1300C > T (p.Gln434Ter) }\end{array}$ & KRT10 & BIE & $\begin{array}{l}\text { Pathogenic } \\
\text { (Apr 1, 2006) }\end{array}$ & 17 & 38975842 & 17 & 40819590 & 29764 & 38719 \\
\hline 18 & $\begin{array}{l}\text { NM_000421.3(KRT10): } \\
\text { c.1281C > A (p.Cys427Ter) }\end{array}$ & KRT10 & BIE & $\begin{array}{l}\text { Pathogenic } \\
\text { (Jul 1, 2008) }\end{array}$ & 17 & 38975861 & 17 & 40819609 & 29765 & 38720 \\
\hline 19 & $\begin{array}{l}\text { NM_000421.3(KRT10): } \\
\text { c.494G > C (p.Arg165Pro) }\end{array}$ & KRT10 & Not provided & $\begin{array}{l}\text { Likely pathogenic } \\
\text { (Sep 1, 2016) }\end{array}$ & 17 & 38978344 & 17 & 40822092 & 432167 & 426220 \\
\hline 20 & $\begin{array}{l}\text { NM_000421.3(KRT10): } \\
\text { c.482T > C (p.Leu161Ser) }\end{array}$ & KRT10 & $\mathrm{BIE}$ & $\begin{array}{l}\text { Pathogenic } \\
\text { (Aug 21, 1992) }\end{array}$ & 17 & 38978356 & 17 & 40822104 & 14569 & 29608 \\
\hline 21 & $\begin{array}{l}\text { NM_000421.3(KRT10): } \\
\text { c.479A > C (p.Tyr160Ser) }\end{array}$ & KRT10 & Not provided & $\begin{array}{l}\text { Pathogenic } \\
\text { (Apr 2, 2018) }\end{array}$ & 17 & 38978359 & 17 & 40822107 & 66178 & 77075 \\
\hline 22 & $\begin{array}{l}\text { NM_000421.3(KRT10): } \\
\text { c.478T > G (p.Tyr160Asp) }\end{array}$ & KRT10 & BIE & $\begin{array}{l}\text { Pathogenic } \\
\text { (Feb 1, 1994) }\end{array}$ & 17 & 38978360 & 17 & 40822108 & 14572 & 29611 \\
\hline 23 & $\begin{array}{l}\text { NM_000421.3(KRT10): } \\
\text { c.467G > A (p.Arg156His) }\end{array}$ & KRT10 & BIE & $\begin{array}{l}\text { Pathogenic } \\
\text { (Sep 20, 2017) }\end{array}$ & 17 & 38978371 & 17 & 40822119 & 14573 & 29612 \\
\hline 24 & $\begin{array}{l}\text { NM_000421.3(KRT10): } \\
\text { c.460A > C (p.Asn154His) }\end{array}$ & KRT10 & BIE & $\begin{array}{l}\text { Pathogenic } \\
\text { (Feb 1, 1994) }\end{array}$ & 17 & 38978378 & 17 & 40822126 & 14571 & 29610 \\
\hline
\end{tabular}

EBH-DM epidermolysis bullosa herpetiformis-Dowling Meara, EBS epidermolysis bullosa simplex, El erythroderma ichthyosiform, BIE Bullous ichthyosiform erythroderma

Italicized words indicate comparison of identical mutation obtained in our study (psoriasis) with other skin disease

Validation of mutation and their pathogenicity using Mutation Surveyor and Alamut Visual software

To validate and confirm the mutation, we did in silico analysis of all keratin sequences obtained in these patients by using Mutation Surveyor software. Similar to Sanger sequence results, in silico analysis also showed nine and seven missense mutations in K14 and K10, respectively, as well as no missense mutation was found in 


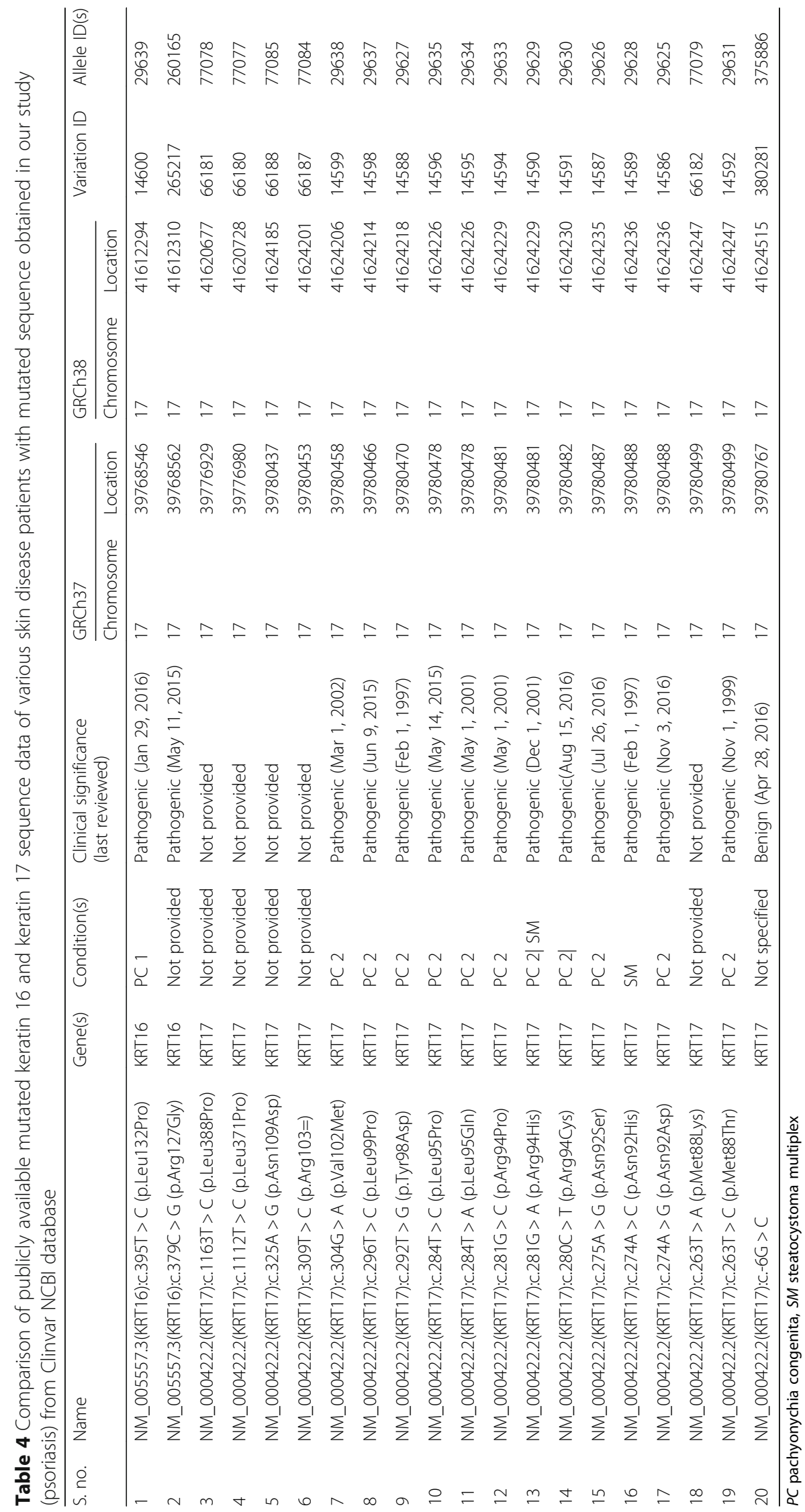


K16 and K17 in mild psoriasis (Fig. 2). Also, in moderate psoriasis, a similar mutation pattern was shown (Figs. 3 and 4) using Mutation Surveyor software. The mutation's pathogenicity was predicted by using Alamut Visual software; we found about 34 and 15\% of $\mathrm{K} 14$ and $\mathrm{K} 10$ mutated sequences in mild psoriasis that were predicted to be tolerated, and the remaining sequences were predicted to have damaging effect. Based on Mutation Assessor, all mutated sequences in mild psoriasis have medium effect on the alteration of these protein functions (Table 5; Additional file 1: Fig. S1) where, as in moderate psoriasis, all mutated sequences are predicted to have a damaging role with high effect on the alteration of protein functions (Table 6; Additional file 1: Fig. S2). Totally, we identified 44 mutations among which 16 mutations were found in both mild and moderate psoriasis, whereas 28 mutations were found only in moderate psoriasis.

\section{Comparison of mutated keratins with ExAC databases}

When we compared K14, K10, K16, and K17 missense mutated variants in ExAC database with their respective K14, K10, K16, and K17 mutated variants observed in our psoriasis patients, we perceived that one K14 c1237G > A variant with MAF 0.01 and one K17 c986C $>$ T variant with MAF $<0.001$ existed in the ExAC database; additionally, none of the K10 and K16 variants were found to occur in the ExAC database. Based on the analysis, our result showed that $99 \%$ of K14 and K17 and $100 \%$ of $\mathrm{K} 10$ and $\mathrm{K} 16$ missense mutations in our psoriasis patients were considered to be as novel missense mutation which did not exist in the ExAC database. These novel mutations might be one of the reasons causing severe damage in psoriasis patients (Additional file 2: Table S1).

\section{Identification of deleterious mutations}

Keratin 14, 10, 16, and 17 CDS region of amino acid sequence in Fasta format and 44 missense mutations, which were obtained from Mutation Surveyor and Visual Alamut, were loaded to PredictSNP1.0, and all available integrated tools were selected for prediction. PredictSNP1.0 provided predictions for each integrated tool and a consensus prediction as percentages (expected accuracies) and the effect of mutation on protein function as "neutral" and "deleterious" by PredictSNP and all the integrated tools, except for nsSNPAnalyzer, which did not give any prediction for any mutations. In mild psoriasis, about $70 \%$ of mutated sequences in both $\mathrm{K} 14$ and $\mathrm{K} 10$ were found to be deleterious, whereas in moderate psoriasis, all K14 and K10; one K16 and six K17 mutated sequences were found to be deleterious. Out of 44 mutations, 33 mutations were predicted to be as deleterious by PredictSNP and all the integrated tools, except for nsSNPAnalyzer, which did not give any prediction for any mutations (Tables 7 and 8).

\section{Location of the deleterious mutations on the secondary structure and 3D structure of keratin protein}

Position of these deleterious mutations in the keratin secondary and 3D structure is important because amino acid sequences of keratin are mainly involved in the assembly of keratin filaments and also binding of keratins and keratin filaments to cell adhesion complexes or signaling molecules. The secondary structure of these keratin proteins has three sub-domains, namely, head domain, central $\alpha$-helical rod domain, and tail domain. The rod domain is mainly composed of sub-domain coils $1 \mathrm{~A}, 1 \mathrm{~B}, 2 \mathrm{~A}$, and $2 \mathrm{~B}$ connected by linkers L1, L12, and L2 (Fig. 5a). We detected that these 33 mutations were located in the rod domain of these keratin proteins. The deleterious mutations in the rod domain were

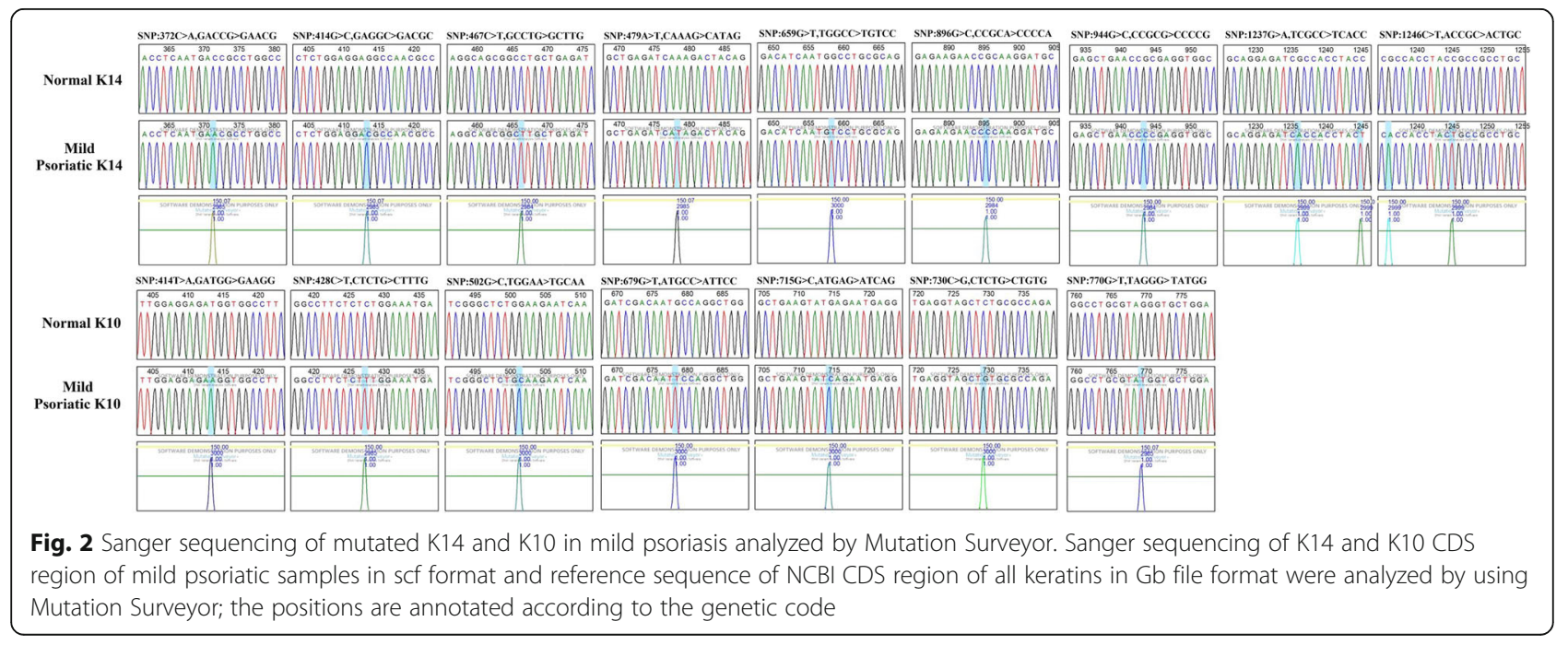




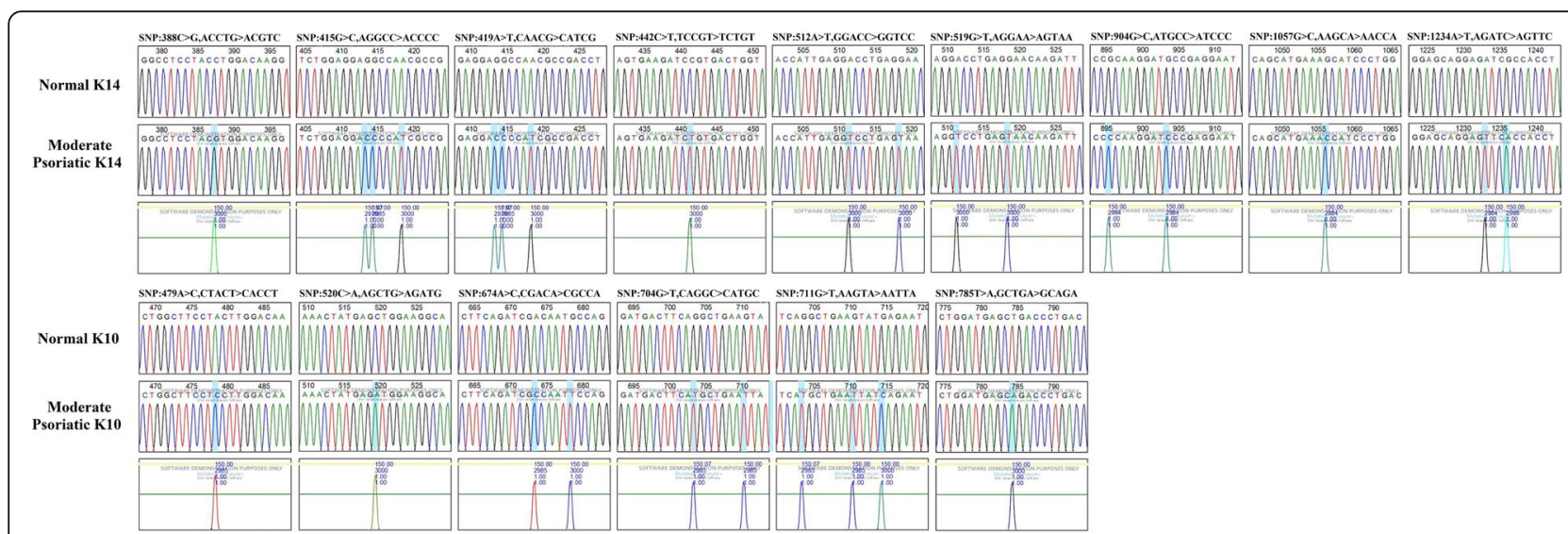

Fig. 3 Sanger sequencing of mutated K14 and K10 in moderate psoriasis analyzed by Mutation Surveyor. Sanger sequencing of K14 and K10 CDS region of moderate psoriatic samples in scf format and reference sequence of NCBI CDS region of all keratins in Gb file format were analyzed by using Mutation Surveyor; the positions are annotated according to the genetic code

mainly noticed in coil 1 and 2 regions, which are critical for the protein activity and structure of these keratins.

Pathogenic K14 mutated sequences are mainly located in exon 1 and exon 6. In keratin 14, exon 1 (1-586 nucleotide) mainly forms the head and rod (coil 1A, L1, and $1 \mathrm{~B})$ region and exon 6 (1115-1335 nucleotide) forms the coil 2 of the rod domain. In K14, coil $1 \mathrm{~A}$ region has five mutated amino acids, L1 region has one mutated amino acid, coil 1B has three mutated amino acids, and coil 2 region has six mutated amino acids. All appeared in close proximity in the folded protein (Fig. $5 \mathrm{~b}$ ).

Exons 1 and 2 are the major regions affected by the mutation in K10; they mainly form the head and rod domain region of $1 \mathrm{~A}$ and $1 \mathrm{~B}$. We found three mutations in coil $1 \mathrm{~A}$ region and eight mutations in coil $1 \mathrm{~B}$ region of the rod domain. In $\mathrm{K} 16$, one mutation in coil $1 \mathrm{~B}$ region was found to be deleterious. However, in K17, one mutation in coil $1 \mathrm{~B}$ region of peptide epitope $\mathrm{S} 2$, two mutations in $1 \mathrm{~B}$ region of peptide epitope $\mathrm{S} 3$, and three mutations in coil 2 region of peptide epitope $S 4$ of the rod domain were found (Fig. 5b) The deleterious mutations in the rod domain of all these keratins were mainly noticed in coil 1 and 2 regions, which are critical for the protein activity and structure of these keratins.

Our results showed that the predicted deleterious mutations highly located in the $\alpha$-helical rod domain, which forms a coiled structure to these keratins, are important to maintain the structural integrity of the skin.

\section{Effect of deleterious mutation on keratin protein stability} After predicting the deleterious effect and position of these mutated sequences in protein, it is imperative to analyze the stability of this protein. Therefore, we have

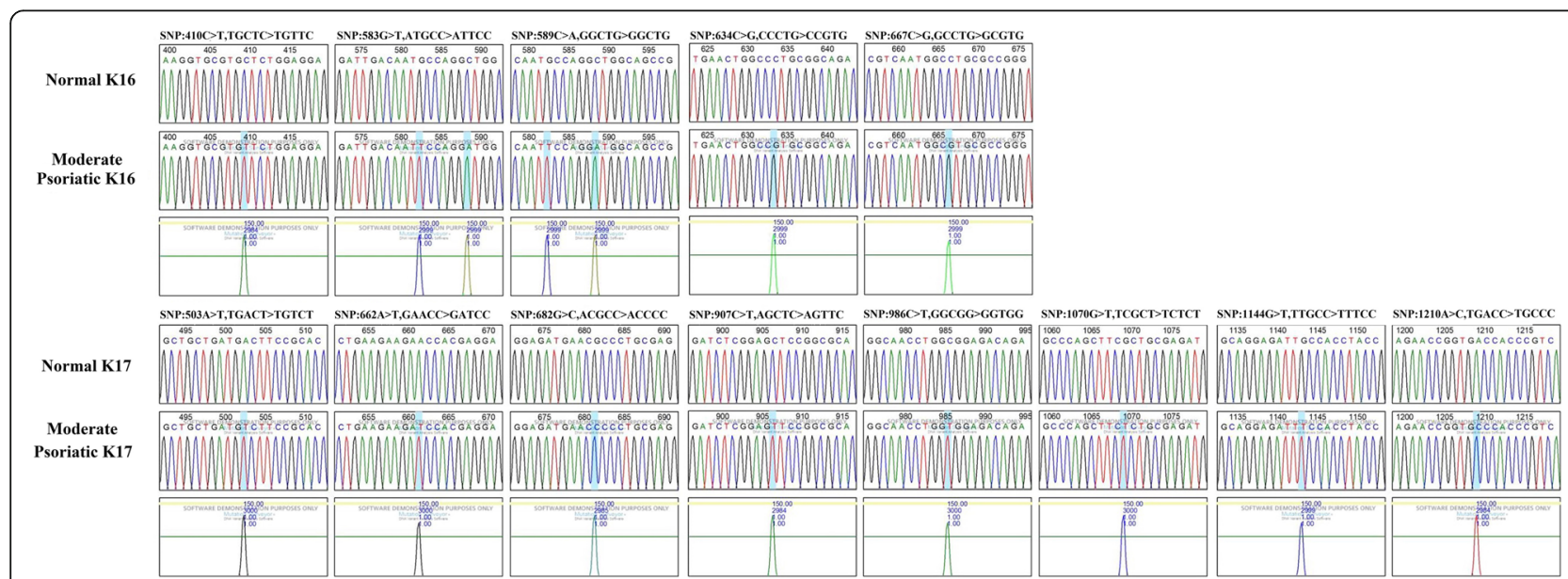

Fig. 4 Sanger sequencing of mutated K16 and K17 in moderate psoriasis analyzed by Mutation Surveyor. Sanger sequencing of K16 and K17 CDS region of moderate psoriatic samples in scf format and reference sequence of NCBI CDS region of all keratins in Gb file format were analyzed by using Mutation Surveyor; the positions are annotated according to the genetic code 


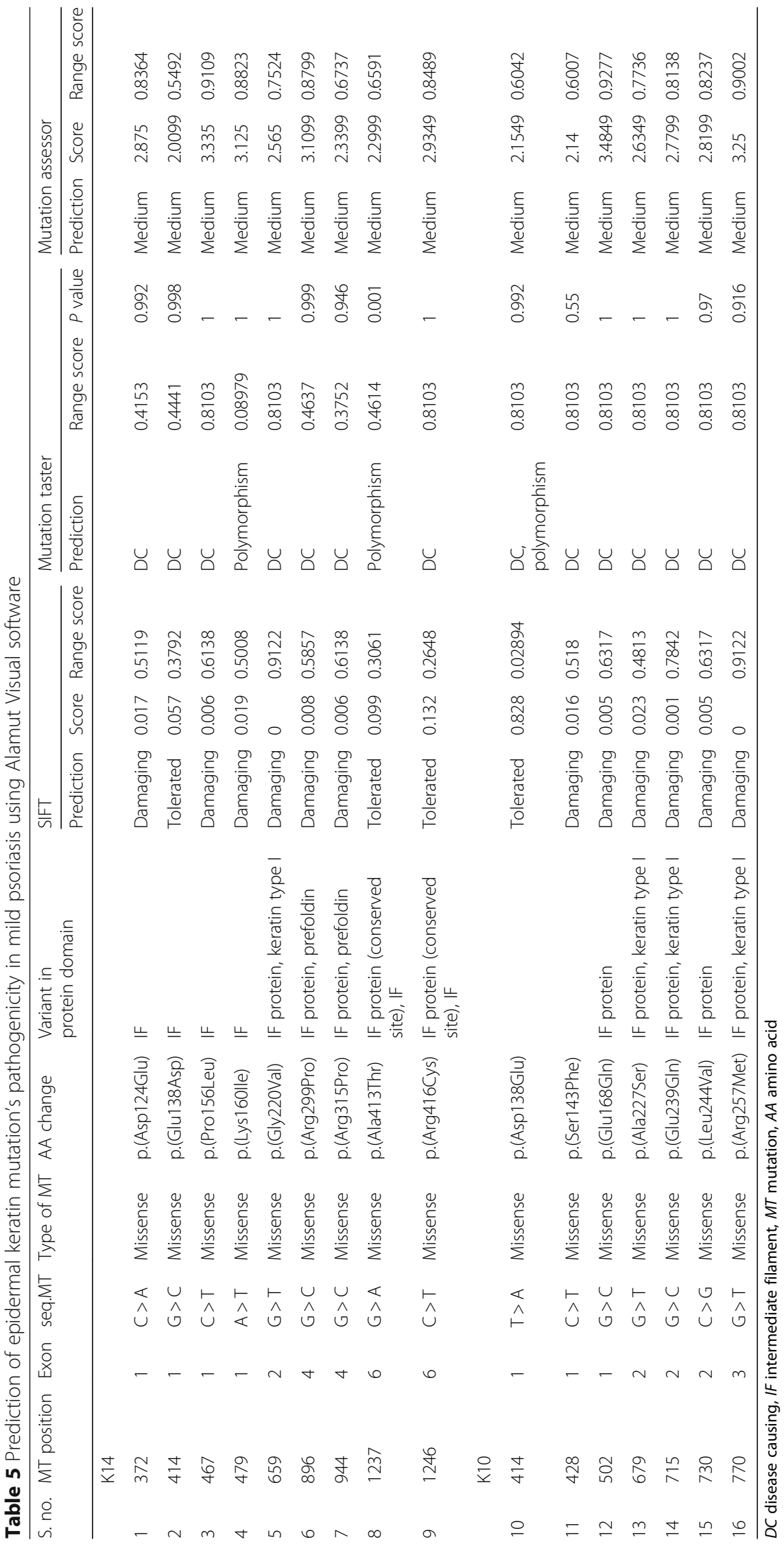




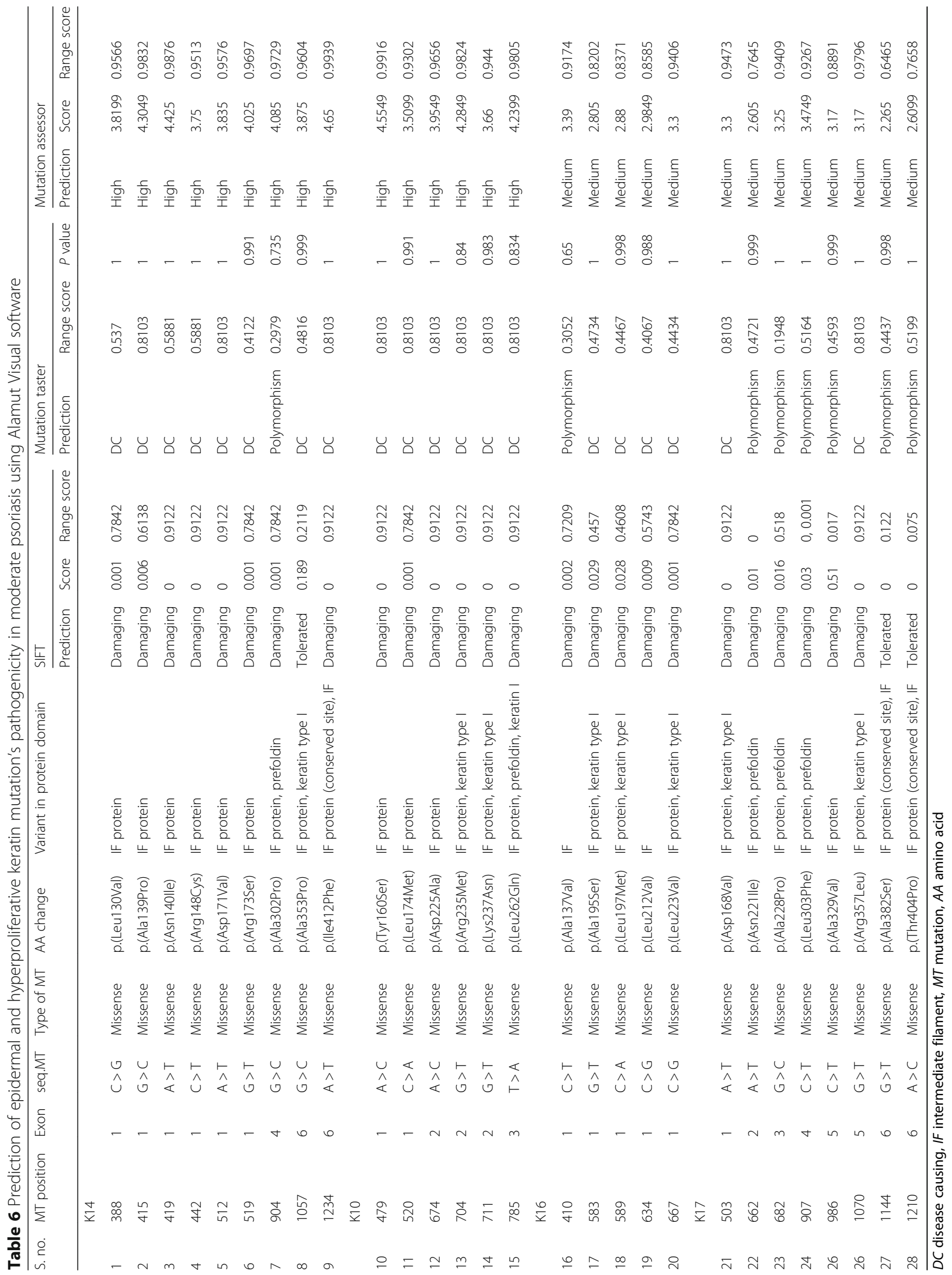




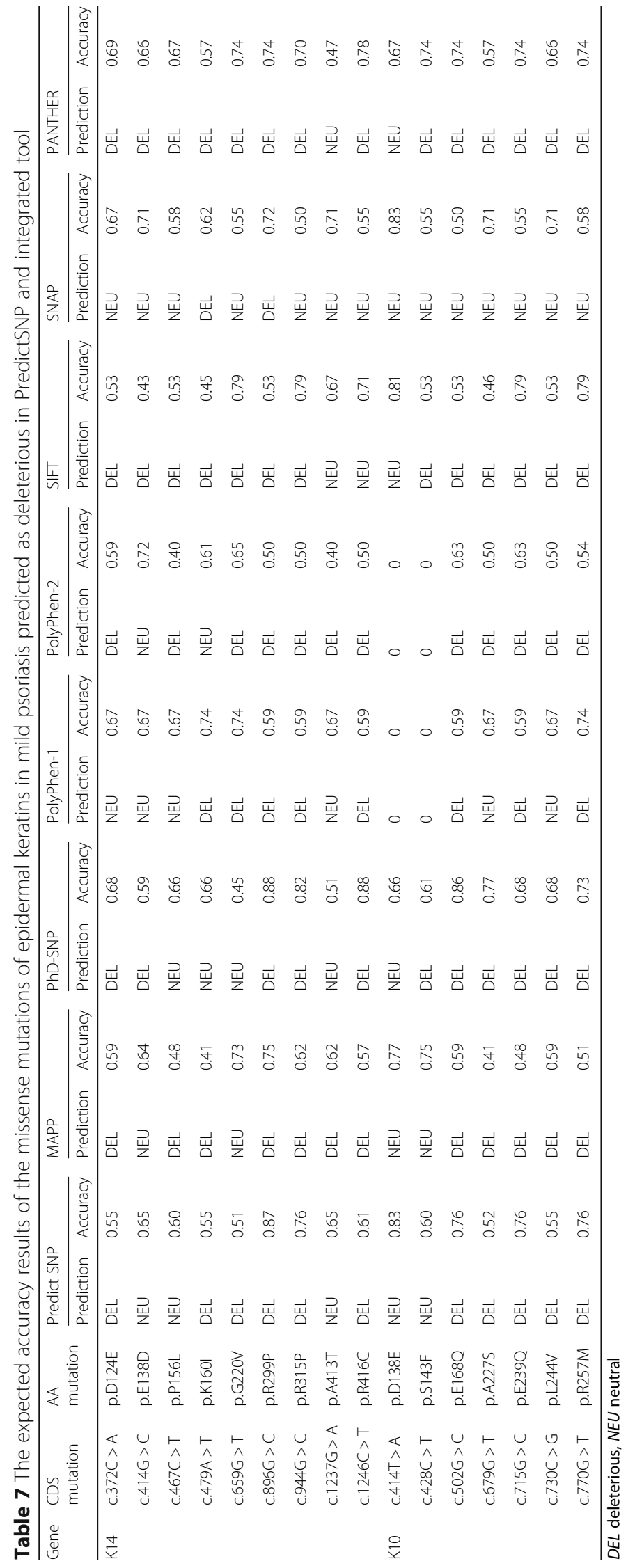




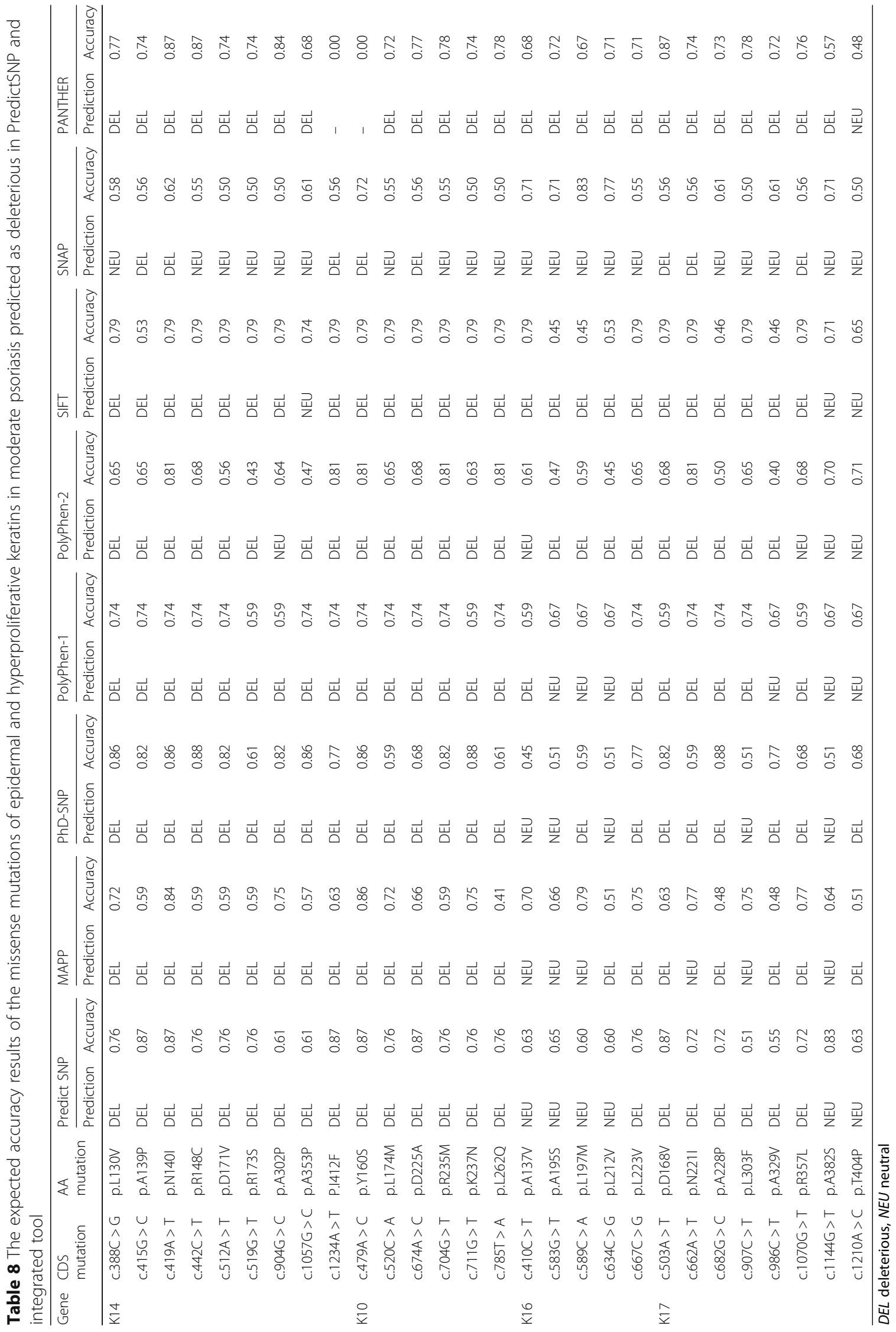




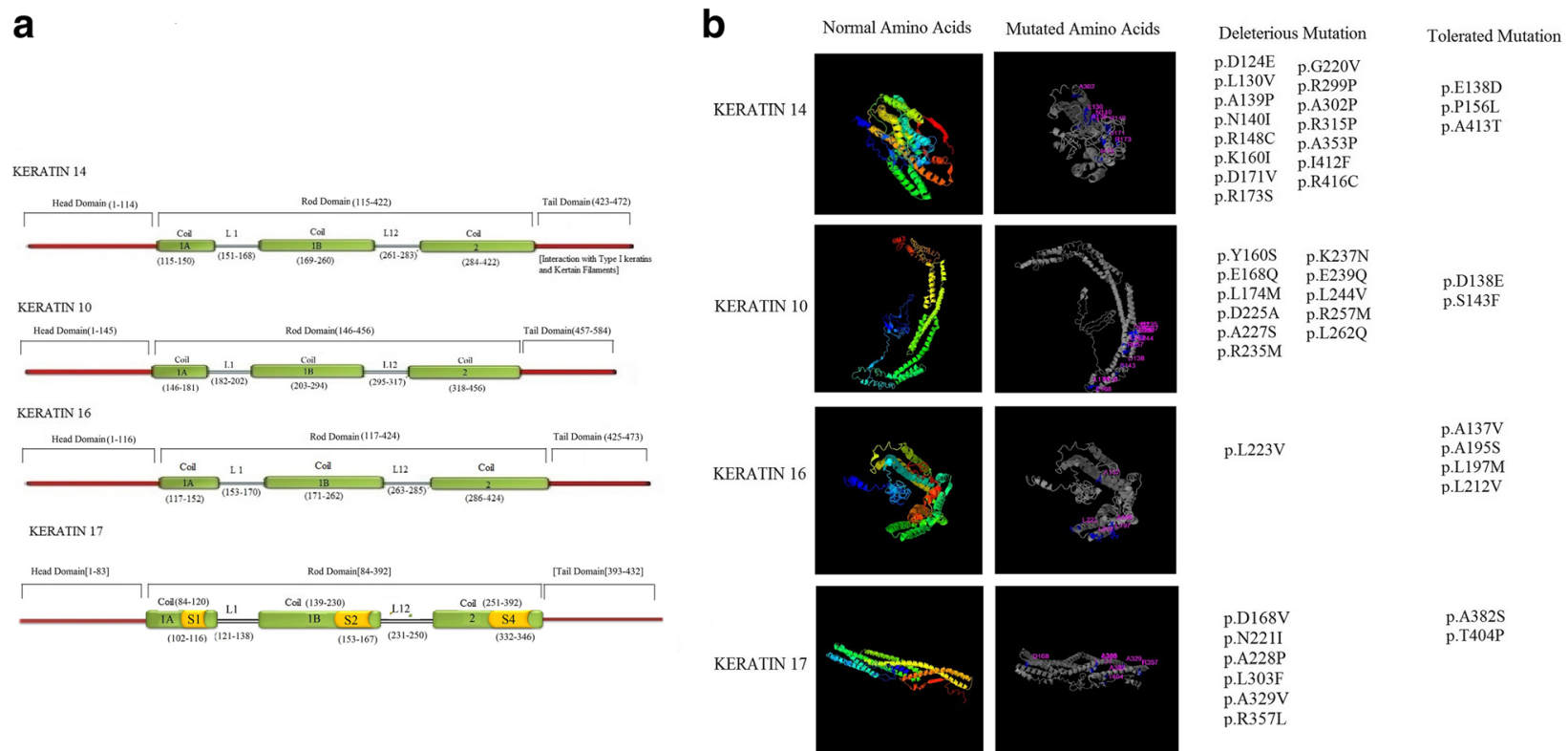

Fig. 5 Protein structure of epidermal and hyperproliferative keratins. a Schematic representation of secondary structure of all four keratins with their domain and sub-domain, whereas, $S$ = peptide epitope and $L=$ linker. $\mathbf{b}$ Specific regions of 33 deleterious mutation localizations. The figures in the left side are the 3D structure of all four keratin CDS regions. The figures in the right side are the 3D structures of domains with mutated residues. The mutated residues are numbered according to their position on the regions. The position of mutated amino acids (aa) on all four keratins and on CDS regions are provided

analyzed the protein stability of these 33 deleterious mutated sequences on MUpro server and I-Mutant 2.0. Our results showed that in mild psoriasis, about two third of $\mathrm{K} 14$ and $\mathrm{K} 10$ mutation decrease the protein stability. However, in moderate stage, $90 \%$ of all mutated K14, K10, K16, and K17 sequences showed decreased protein stability (Table 9).

\section{Immunofluorescence analysis of K14, K10, K16, and K17 antibodies}

Our immunofluorescence analysis of normal epidermis shows nuclei stained blue with DAPI throughout all the epidermal layers, whereas K14-positive cells are found only in the basal epidermal cell. Merging discloses coexpression of K14 and DAPI nuclear stain in most of the basal epidermal cells in control samples. In lesional samples, no staining of K14 was seen in the basal layer, whereas DAPI staining was seen throughout the elongated rete ridges, and merged results show there is no staining of K14 in the basal layer (Fig. 6).

DAPI stain was seen throughout all the epidermal layers, and K10 antibodies were stained in the spinosum of the epidermal layer in normal epidermis. K10-positive cells were seen marginally in the elongated rete ridges of the suprabasal epidermal layer. Merging of two stains shows marginal expression of $\mathrm{K} 10$ and strong DAPI staining in the nuclei of cells of the suprabasal epidermal layer (Fig. 6).
To confirm the expression of abnormal proteins K16 and K17 on the protein level, we performed immunofluorescence analyses in the corresponding control and lesional psoriatic skin samples. These analyses clearly reflected that there is no K16 expression, and blue DAPI stain stained the nuclei present in the normal epidermal layer. Psoriasis samples showed a strong expression of K16 throughout the suprabasal with nuclei stained with DAPI (Fig. 6). In addition, we analyzed there is no K17 protein in the normal epidermal layer, but nuclei were stained with DAPI and merging showed the blue nuclei staining throughout the epidermis, whereas in psoriasis, the K17 protein was seen in the stratum corneum along with DAPI staining (Fig. 6).

\section{Expression of keratins and their correlation with PASI in both mild and moderate psoriases}

In mild psoriatic samples, the mRNA expression of K14 and $\mathrm{K} 10$ was significantly elevated to 2.5 - and 4.4-folds compared to nonlesional, respectively, whereas in moderate case, these expressions were decreased significantly. In contrast to K14 and K10 expression, decrease in K16 and K17 expression was found in mild psoriasis; as the disease progresses in moderate psoriasis, the expression of K16 and K17 significantly elevated at 4.9- and 4.4-folds compared to nonlesional, respectively (Fig. 7a). Further, these results were confirmed by the Western blot analysis (Fig. 7b). We strongly believed that the changes in keratin 
Table 9 Protein stability change prediction results of MUpro and I-Mutant2.0 for the 33 deleterious missense mutations of epidermal and hyperproliferative keratins in mild and moderate psoriasis patients

\begin{tabular}{|c|c|c|c|c|c|c|c|c|c|}
\hline \multirow[t]{2}{*}{ Stages of psoriasis } & \multirow[t]{2}{*}{ Gene } & \multirow[t]{2}{*}{ CDS mutation } & \multirow[t]{2}{*}{ AA mutation } & \multicolumn{4}{|l|}{ MUpro } & \multicolumn{2}{|c|}{ I-Mutant 2.0} \\
\hline & & & & SVM & SVMCS & NN & NNCS & Stability & DDG \\
\hline \multirow[t]{11}{*}{ Mild } & \multirow[t]{6}{*}{ K14 } & c. $372 C>A$ & p.D124E & Increase & 0.05 & Increase & 0.71 & Decrease & -0.52 \\
\hline & & c. $479 \mathrm{~A}>\mathrm{T}$ & p.K160l & Decrease & -0.54 & Decrease & -0.89 & Decrease & 0.61 \\
\hline & & c.659G > T & p.G220V & Increase & 0.41 & Increase & 0.65 & Decrease & -0.46 \\
\hline & & c. $896 \mathrm{G}>\mathrm{C}$ & p.R299P & Decrease & -0.57 & Decrease & -0.75 & Decrease & -2.22 \\
\hline & & $C .944 G>C$ & p.R315P & Decrease & -0.53 & Decrease & -0.86 & Decrease & -1.26 \\
\hline & & c. $1246 C>T$ & p.R416C & Decrease & -0.16 & Decrease & -0.58 & Decrease & -0.3 \\
\hline & \multirow[t]{5}{*}{ K10 } & $c .502 G>C$ & p.E168Q & Increase & 0.39 & Increase & 0.70 & Decrease & -0.01 \\
\hline & & c.679G > T & p.A227S & Decrease & -1 & Decrease & -0.71 & Decrease & -0.19 \\
\hline & & c.715G >C & p.E239Q & Decrease & -0.12 & Decrease & -0.64 & Decrease & -0.28 \\
\hline & & c. $730 C>G$ & p.L244V & Decrease & -1 & Decrease & -0.94 & Decrease & -2.03 \\
\hline & & c.770G > T & p.R257M & Increase & 0.53 & Increase & 0.81 & Decrease & -0.47 \\
\hline \multirow[t]{22}{*}{ Moderate } & \multirow[t]{9}{*}{ K14 } & c. $388 C>G$ & p.L130V & Decrease & -1 & Decrease & -1 & Decrease & -1.67 \\
\hline & & $c .415 G>C$ & p.A139P & Decrease & -0.63 & Decrease & -0.88 & Decrease & -1.89 \\
\hline & & C. $419 \mathrm{~A}>\mathrm{T}$ & p.N140l & Decrease & -0.23 & Decrease & -0.67 & Increase & 1.57 \\
\hline & & c. $442 C>T$ & p.R148C & Decrease & -1 & Decrease & -1 & Decrease & -0.28 \\
\hline & & c. $512 \mathrm{~A}>\mathrm{T}$ & p.D171V & Decrease & -0.37 & Decrease & -1 & Decrease & -0.36 \\
\hline & & c.519G $>\mathrm{T}$ & p.R173S & Decrease & -1 & Decrease & -1 & Decrease & -2.37 \\
\hline & & c. $904 G>C$ & p.A302P & Increase & 0.63 & Increase & 0.73 & Decrease & -3.34 \\
\hline & & c. $1057 G>C$ & p.A353P & Decrease & -0.58 & Decrease & -0.65 & Increase & -0.65 \\
\hline & & c. $1234 \mathrm{~A}>\mathrm{T}$ & P.I412F & Decrease & -1 & Decrease & -0.69 & Decrease & -0.95 \\
\hline & \multirow[t]{6}{*}{ K10 } & C. $479 A>C$ & p.Y160S & Decrease & -0.47 & Decrease & -0.64 & Decrease & -1.16 \\
\hline & & C. $520 C>A$ & p.L174M & Decrease & -1 & Decrease & -1 & Decrease & 0.12 \\
\hline & & c. $674 \mathrm{~A}>C$ & p.D225A & Decrease & -0.39 & Decrease & -0.78 & Decrease & -0.76 \\
\hline & & c. $704 \mathrm{G}>\mathrm{T}$ & p.R235M & Decrease & -0.45 & Decrease & -0.89 & Decrease & -0.59 \\
\hline & & $c .711 G>T$ & p.K237N & Decrease & -0.60 & Decrease & -1 & Increase & 0.26 \\
\hline & & c. $785 \mathrm{~T}>\mathrm{A}$ & p.L262Q & Decrease & -1 & Decrease & -1 & Decrease & -1.82 \\
\hline & K16 & c. $667 C>G$ & p.L223V & Decrease & -1 & Decrease & -1 & Decrease & -1.39 \\
\hline & \multirow[t]{6}{*}{ K17 } & c. $503 \mathrm{~A}>\mathrm{T}$ & p.D168V & Decrease & -0.30 & Decrease & -0.60 & Decrease & -0.73 \\
\hline & & c. $662 \mathrm{~A}>\mathrm{T}$ & p.N221I & Decrease & -0.70 & Increase & 0.62 & Increase & 1.64 \\
\hline & & c. $682 \mathrm{G}>\mathrm{C}$ & p.A228P & Decrease & -0.04 & Increase & 0.61 & Decrease & -2.48 \\
\hline & & c. $907 \mathrm{C}>\mathrm{T}$ & p.L303F & Decrease & -1 & Decrease & -1 & Decrease & 0.95 \\
\hline & & c. $986 C>\mathrm{C}$ & p.A329V & Decrease & -0.34 & Decrease & -0.88 & Decrease & 0.12 \\
\hline & & c. $1070 \mathrm{G}>\mathrm{T}$ & p.R357L & Increase & 0.15 & Increase & 0.68 & Increase & 0.66 \\
\hline
\end{tabular}

CDS coding sequences, AA amino acid, SVM support vector machine, SVMCS SVM confidence score, NN neural network, NNCS neural network confidence score, $D D G$ free energy change value

expression in the psoriatic epidermis might be due to some pathogenic variants in these keratin genes.

Correlation analysis of keratins and PASI in two stages of psoriasis is shown in Fig. 8. There was a significant inverse correlation between normal epidermal keratins K14 and K10 and PASI score $(r=-0.998 ; r=-0.996$; $P<0.001)$, respectively, in mild psoriasis, whereas the abnormal hyperproliferative keratins K16 and K17 showed a positive correlation with PASI score $(r=0.999 ; r=0.997$; $P<0.001)$ in mild psoriasis. In moderate case, Spearman's coefficient correlation analysis showed a negative correlation between K14 and K10 and PASI score $(r=-0.993$; $r=-0.997 ; \quad P<0.001)$, respectively, and showed a strong positive correlation between K16 and K17 with PASI score, which was statistically significant $(r=0.998$; $r=0.998 ; P<0.001)$, respectively. We report that the 


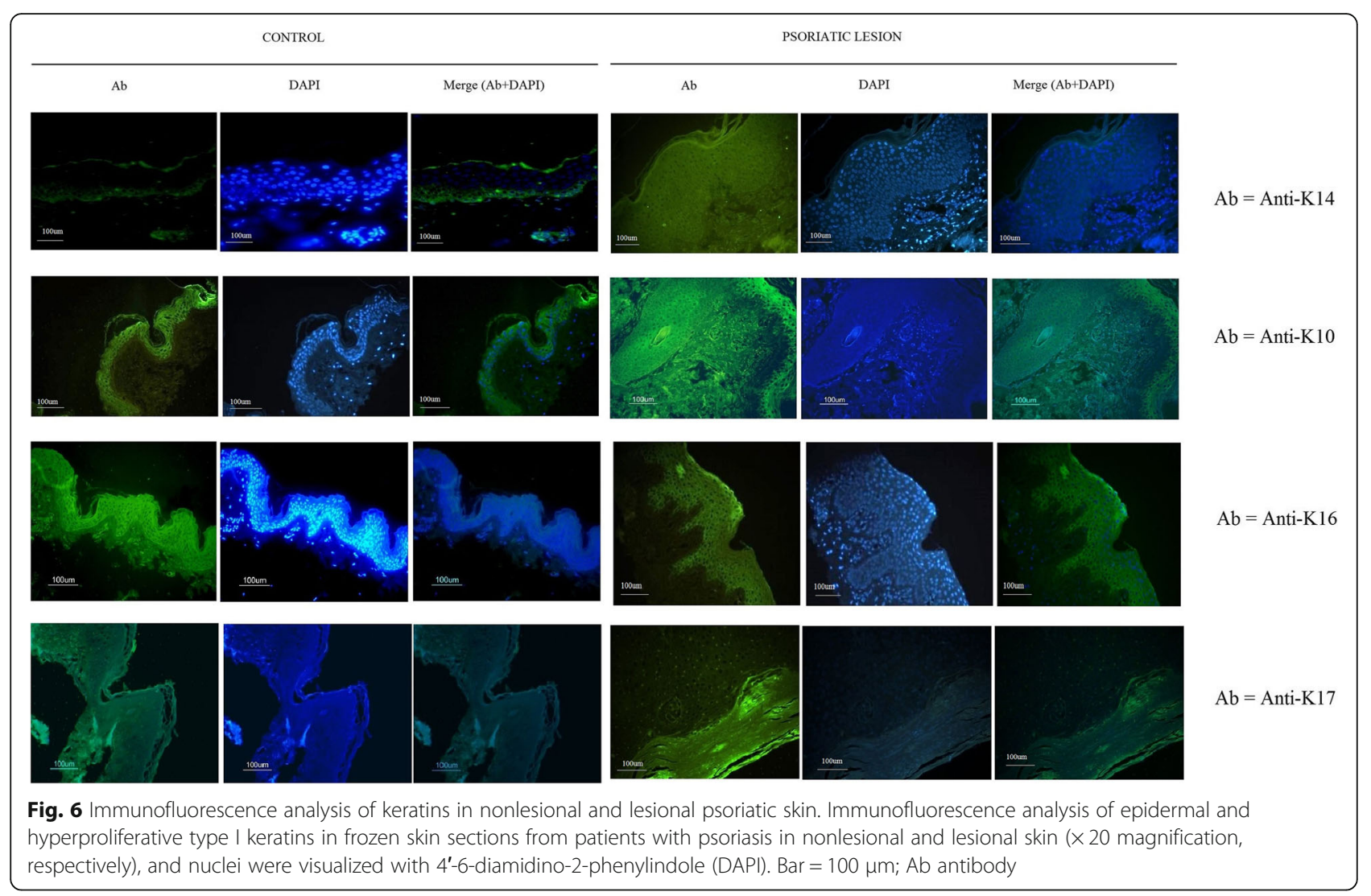

degree of severity of the clinical phenotype has been directly linked to the position of the pathogenic mutation along the keratin polypeptide backbone.

\section{Discussion}

The epidermal barrier is formed by keratinocytes contributing tight junctions and the cornified envelope [1]. Barrier dysfunction and cutaneous sensitization can give rise to chronic inflammatory disorders like atopic eczema and psoriasis. Keratin plays an important role in maintaining epidermal barrier as well as in the formation of tight junction and cornified envelope in skin [40]. However, mutations of keratins in psoriasis have not been fully investigated. In this present study, we have identified 18 mutations in the CDS region of K14 out of which nine mutations are slightly pathogenic variants in the psoriatic samples. Numerous mutations in $\mathrm{K} 5$ and K14 identified in EBS are dominant pathogenic mutations. There are a few cases of recessive mutations which nearly all lead to loss of function or a natural knockout in K14 [41-45]. Related to our result, studies showed that in EBS, the pathogenic mutations of K14 usually occur within two segments (1A and $2 \mathrm{~B}$ ) of the rod domain [46]. Cells expressing mutated K14 are more prone to stress damage and resistance to apoptosis [47, 48]. Thus, we propose that the mutation of K14 in psoriatic skin might lead to "unnatural" keratin pair; this will drastically alter the assembly of network filament as well as mechanical support in epidermal skin and also increase the degradation of keratin filaments by various stressors, all these leading to acanthosis in psoriasis.

Moreover, we have also identified 13 mutated sequences in keratin 10 protein. Of these, six sequences are considered as highly pathogenic, and the remaining seven sequences are considered as slightly pathogenic. Similar to our study, in epidermal hyperkeratosis, most of the pathogenic missense mutations of K10 usually occur within highly conserved regions of the $\alpha$-helical rod domains and the non-helical HI domain [49, 50]. Reichelt et al. [51] reported that defects in keratin 10 gene may lead to hyperproliferation of basal cells, induction of c-Myc, cyclin D1, 14-3-36, K6, and K16. K10 is essential to control cell proliferation and also for the expression of filaggrin and cornified envelope proteins [52]. In epidermolytic ichthyosis (EI) patients, mutation of K10 proteins showed increased proliferation of suprabasal keratinocytes which leads to ichthyosiform lesions, suprabasal cytolysis, blister formation, and hyperkeratosis $[53,54]$. Thus, the mutation in K10 might cause irregularly shaped pathognomonic keratin intermediate filament (KIF) clumps in suprabasal keratinocytes which disrupt the structural stability in the suprabasal 


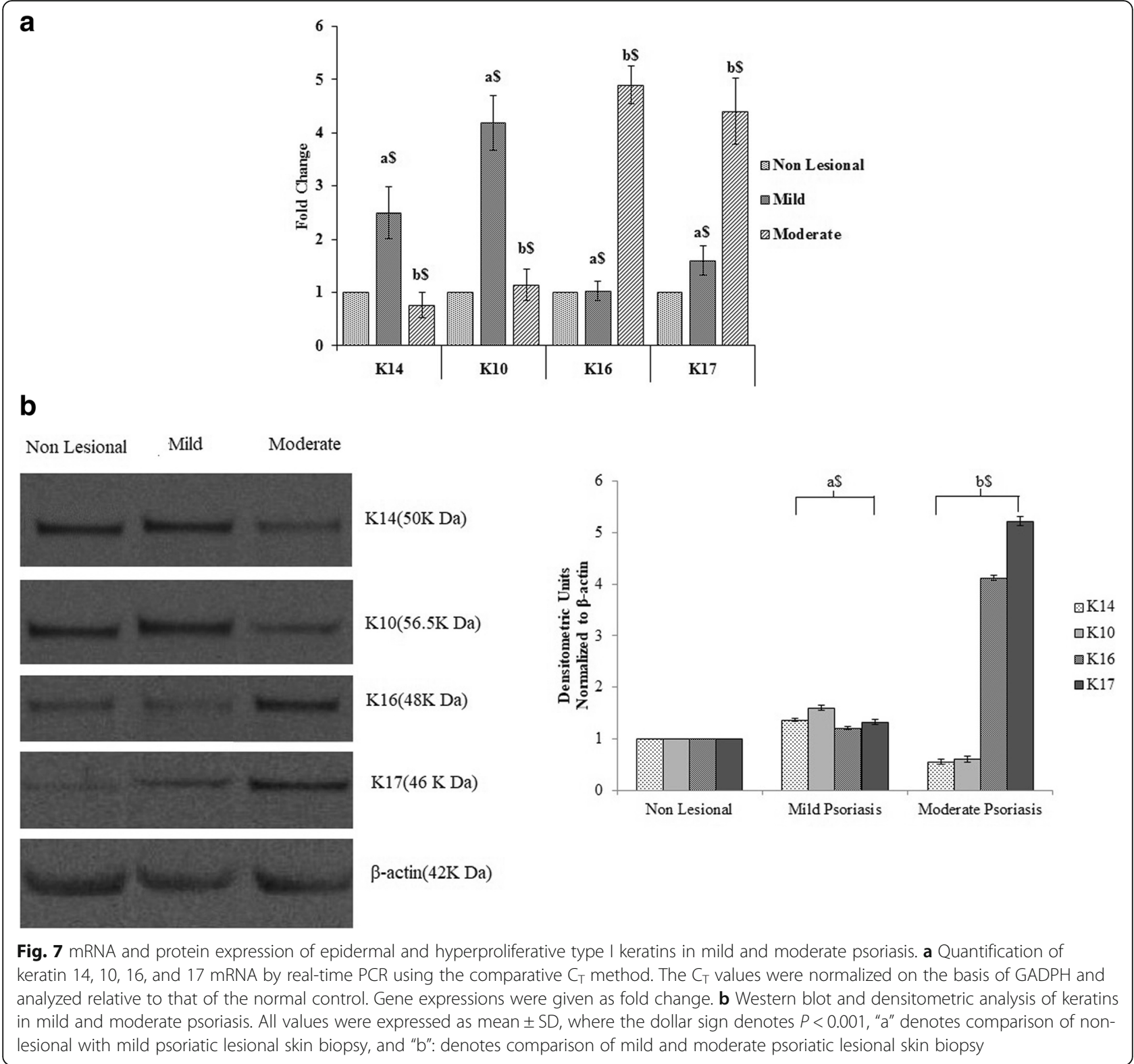

keratinocytes and also increase cyclin D, cyclin E, and phosho-Akt levels, all of which drive to hyperproliferation of keratinocytes in psoriasis.

Rapid psoriasis recurrence or new morphologies have been reported after discontinuation of traditional therapy or biological [55-58]. Interestingly, psoriatic lesions preferentially appeared at sites of wound healing (Koebner phenomenon). These relapse and Koebner phenomenon in psoriasis might be due to the variants in hyperproliferative keratin genes. In order to reveal this, we studied K16 and K17 psoriatic sequences for mutational analysis. In this, we did not find any mutation and expression of these keratins in mild psoriasis. As disease progresses, we found a pathogenic variant of $\mathrm{K} 16$ and $\mathrm{K} 17$ in moderate psoriasis. Early studies showed that an inherited dominant mutation in $\mathrm{K} 16$ and $\mathrm{K} 17$ is causative for pachyonychia congenita (PC) [59-63]. Lessard et al. [64] showed that in PC, loss of K16 function in mice causes the development of prominent calluses on the plantar side of the front and hind paws, which significantly compromise mobility and eventually lead to overt loss of barrier properties and also deletion of K16-produced spontaneously arising palmoplantar keratoderma-like lesions in mice. However, some studies have reported that in the context of epidermal wound healing, K16 mainly promotes a reorganization of the cytoplasmic array of keratin filaments, an event that precedes the onset of keratinocyte migration into the wound site [65], and also, K17-associated 


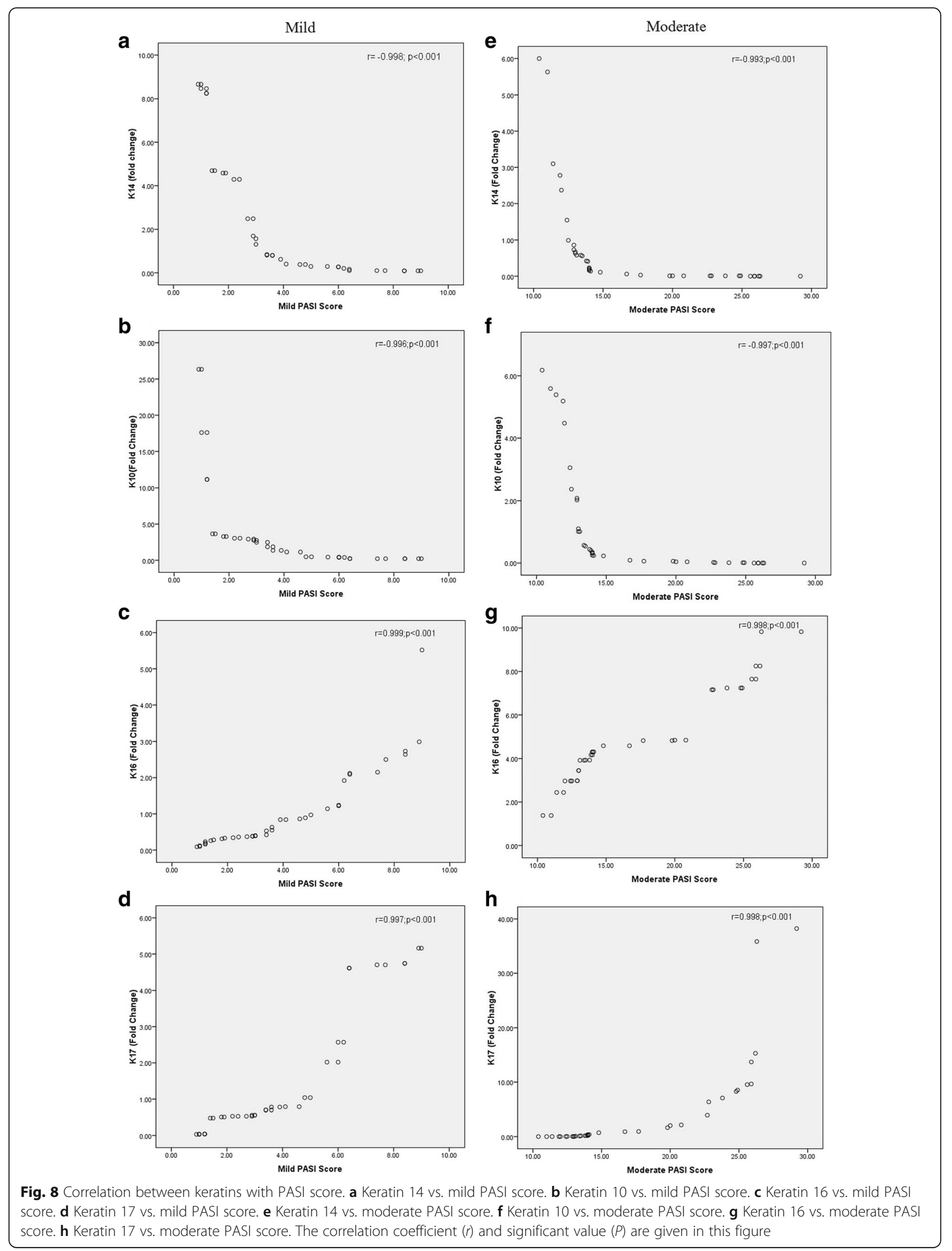


activation process is believed to be essential in reepithelization of the injured area [66]. In contrast to wound healing, K17 and K16 expression in psoriasis failed to resolve the deregulated inflammatory response which leads to the persistent activation of keratinocytes; these responses might be due to the mutation in these genes. Thus, mutation in K16 and K17 in psoriasis might be one of the factors for disease severity and Koebner phenomenon, accompanied with early relapse even with therapy.

In this study, we showed increased K14 and K10 expression at protein and mRNA levels in mild psoriatic skin biopsies compared to nonlesional skin biopsies; in contrast to this, moderate lesional biopsy showed decreased expression of K14 and K10. Similar to our results, other studies also showed that in lesional biopsy, the level of K14 was considerably higher with downregulation of K10 compared with normal epidermis [11, 13, 67]. Also, we found that the hyperproliferative keratin K16 and K17 expressions were low in mild psoriasis; as diseases progress, these expressions were increased in moderate psoriasis compared to nonlesional. Consistent with our results, many authors also showed an upregulation of K6 and K16 $[68,69]$ in psoriatic epidermis. Similarly, a study by de Jong et al. [69] also showed the overexpression of K17 in psoriatic epidermis. Earlier reports said that the K17 is considered as a therapeutic target and marker of antipsoriatic therapies used for the treatment of psoriasis [70, 71]. These finding suggests that the changes in keratin expressions might trigger and exacerbate psoriasis.

Finally, we also found a negative correlation between epidermal keratins and PASI score and positive correlation between hyperproliferative keratins and PASI score; these further added that alteration in these keratins in skin might cause severity of psoriasis. Previous studies have reported that the degree of severity of the clinical phenotype has been directly linked to the position of the pathogenic mutation along the keratin polypeptide backbone, although more recent reports provide some exceptions to this, whereby also milder disease phenotypes are caused by pathogenic mutations in the conserved hot spot region of the keratin genes $[72,73]$. We demonstrate that the novel mutation of keratins found in psoriasis patients after comparison with ExAC database will be considered as efficient filtering of candidate psoriasis-causing variants and are useful for the discovery of human "knockout" psoriasis variants in protein-coding genes. Overall, we strongly believed that these novel keratin mutations in the psoriatic epidermis might be one of the main causative factors for psoriasis.

\section{Conclusion}

Even though there are many highly psoriasis-risk genes identified, in 2009, GWAS have found the importance of keratin pattern in psoriasis. Also, studies have found that keratin plays a critical role in the pathogenesis of psoriasis. Based on all these aspects, we focused on this first and foremost study in which we have identified mutation in K14, K10, K16, and K17 genes in the two stages of psoriasis. Our findings suggest that this mutation leads to decreased expression of highly regulated keratins which in turn causes defective barrier accompanied with acanthosis, hyperplasia, and infiltration of inflammatory mediators in psoriatic epidermis. These findings will offer a clue to better understanding the pathogenesis of psoriasis.

\section{Additional files}

Additional file 1: Figure S1. Comparison of the identified K14 and K10 nucleotide sequences of mild psoriasis obtained in this study with those of respective NCBI CDS sequences using BioEdit software (version 7.2).

The mutated sequences are indicated by red arrows. Figure $\mathbf{S 2}$. Comparison of the identified K14, K10, K16, and K17 nucleotide sequences of moderate psoriasis obtained in this study with those of respective NCBI CDS sequences using BioEdit software (version 7.2). The mutated sequences are indicated by red arrows. (PDF $11608 \mathrm{~kb}$ )

Additional file 2: Table S1. K14, K10, K16, and K17 missense mutated variants retrieved from ExAC database. The mutated sequences identical both in our study and ExAC database are indicated by boldfaced words. (XLSX $54 \mathrm{~kb})$

\section{Abbreviations}

CDS: Coding sequences; EBS: Epidermolysis bullosa simplex; El: Epidermolytic ichthyosis; GWAS: Genome-wide association studies; IF: Intermediate filament; K10: Keratin 10; K14: Keratin 14; K16: Keratin 16; K17: Keratin 17; KIF: Keratin intermediate filament; PC: Pachyonychia congenita; SNP: Single nucleotide polymorphism

\section{Acknowledgements}

We thank all patients who have assisted with this study.

\section{Funding}

The study was supported by the postdoctoral funding grant given by Anhui Medical University, National Natural Science Foundation of China (81602397), and the Natural Science Foundation of Shanghai (15ZR1405700).

\section{Availability of data and materials}

The dataset supporting the conclusions of this article, including raw sequencing and clinical data, is available from authors upon request.

\section{Authors' contributions}

TE performed the experiments and data analysis, interpreted the results, and drafted the manuscript. JS and CZ participated in the sample collection and performed the experiments and data analysis. $F Z$ and $Y Z$ contributed to the sequence analysis. LS and SY contributed to the patients' recruitment. XJZ provided guidance on the experimental design and received funding. All authors read and approved the final manuscript.

\section{Ethics approval and consent to participate}

The study was conducted in accordance with the Helsinki Declaration and received approval from the ethical review board of Anhui Medical University (approval no. 8151101031). Informed written consent from the patients or their legal representatives was obtained prior to inclusion to the study.

Competing interests

The authors declare that they have no competing interests. 


\section{Publisher's Note}

Springer Nature remains neutral with regard to jurisdictional claims in published maps and institutional affiliations.

\section{Author details \\ IInstitute and Department of Dermatology, The First Affiliated Hospital, Anhui Medical University, Hefei, China. ${ }^{2}$ Key Laboratory of Dermatology, Ministry of Education, Anhui Medical University, Hefei, China. ${ }^{3}$ Collaborative Innovation Center for Complex and Severe Dermatosis, Anhui Medical University, Hefei, China. ${ }^{4}$ Institute of Dermatology, Huashan Hospital, Fudan University, Shanghai, China. ${ }^{5}$ Anhui Medical University, 81 Meishan Road, Hefei, Anhui Province, China.}

\section{Received: 22 November 2017 Accepted: 9 May 2018}

Published online: 21 May 2018

\section{References}

1. Simpson CL, Patel DM, Green KJ. Deconstructing the skin: cytoarchitectural determinants of epidermal morphogenesis. Nat Rev Mol Cell Biol. 2011;12: 565-80.

2. Kim S, Coulombe PA. Intermediate filament scaffolds fulfill mechanical, organizational, and signaling functions in the cytoplasm. Genes Dev. 2007; 21:1581-97

3. Magin TM, Vijayaraj P, Leube RE. Structural and regulatory functions of keratins. Exp Cell Res. 2007:313:2021-32.

4. Lane EB, McLean WH. Keratins and skin disorders. J Pathol. 2004;204(4): 355-66.

5. Omary MB, Ku NO, Strnad P, Hanada S. Toward unraveling the complexity of simple epithelial keratins in human disease. J Clin Invest. 2009;119:1794-805.

6. Oriolo AS, Wald FA, Ramsauer VP, Salas PJ. Intermediate filaments: a role in epithelial polarity. Exp Cell Res. 2007;313:2255-64.

7. Fuchs $E$, Cleveland DW. A structural scaffolding of intermediate filaments in health and disease. Science. 1998;279:514-9.

8. Osborn M. Intermediate filaments as histologic markers: an overview. J Invest Dermatol. 1983:81:104s-9s.

9. Nestle FO, Kaplan DH, Barker J. Psoriasis. N Engl J Med. 2009;61:496-509.

10. Fuchs $\mathrm{E}_{1}$ Green $\mathrm{H}$. Changes in keratin gene expression during terminal differentiation of the keratinocyte. Cell. 1980;19:1033-42.

11. Thewes M, Stadler R, Korge B, Mischke D. Normal psoriatic epidermis expression of hyperproliferation-associated keratins. Arch Dermatol Res. 1991;283(7):465-71.

12. Korver JE, van Duijnhoven MW, Pasch MC, et al. Assessment of epidermal subpopulations and proliferation in healthy skin, symptomless and lesional skin of spreading psoriasis. Br J Dermatol. 2006:155(4):688-94.

13. Elango T, Thirupathi A, Subramanian $S$, et al. Methotrexate normalized keratinocyte activation cycle by overturning abnormal keratins as well as deregulated inflammatory mediators in psoriatic patients. Clin Chim Act. 2015:451(Pt B):329-37.

14. Arnold I, Watt FM. C-Myc activation in transgenic mouse epidermis results in mobilization of stem cells and differentiation of their progeny. Curr Biol. 2001;11:558-68.

15. Waikel RL, Kawachi Y, Waikel PA, Wang XJ, Roop DR. Deregulated expression of c-Myc depletes epidermal stem cells. Nat Genet. 2001;28:165-8.

16. Schweizer J, Bowden PE, Coulombe PA, et al. New consensus nomenclature for mammalian keratins. J Cell Biol. 2006:174:169-74.

17. Schweizer J, Langbein L, Rogers MA, Winter H. Hair follicle-specific keratins and their diseases. Exp Cell Res. 2007;313:2010-20.

18. Uitto J, Richard G, McGrath JA. Diseases of epidermal keratins and their linker proteins. Exp Cell Res. 2007:313:1995-2009.

19. de Cid R, Riveira-Munoz E, Zeeuwen PL, et al. Deletion of the late cornified envelope LCE3B and LCE3C genes as a susceptibility factor for psoriasis. Nat Genet. 2009:41(2):211-5.

20. Zhang XJ, Huang W, Yang $S$, et al. Psoriasis genome-wide association study identifies susceptibility variants within LCE gene cluster at 1q21. Nat Genet. 2009;41(2):205-10.

21. Mrowietz U, Kragballe $K$, Reich $K$, et al. Definition of treatment goals for moderate to severe psoriasis: a European consensus. Arch Dermatol Res. 2011 Jan;303(1):1-10.

22. Livak KJ, Schmittgen TD. Analysis of relative gene expression data using real-time quantitative PCR and the 2(-delta deltaC(T)) method. Methods. 2001;25:402-8
23. Dong C, Yu B. Mutation surveyor: an in silico tool for sequencing analysis. Methods Mol Biol. 2011;760:223-37.

24. Kumar P, Henikoff S, Ng PC. Predicting the effects of coding nonsynonymous variants on protein function using the SIFT algorithm. Nat Protoc. 2009;4:1073-81.

25. Alamut ${ }^{\circledR}$ : gene mutation interpretation software: http://www.interactivebiosoftware.com. Accessed 8 Dec 2014.

26. Karbassi I, Maston GA, Love A, et al. A standardized DNA variant scoring system for pathogenicity assessments in Mendelian disorders. Hum Mutat 2016;37(1):127-34.

27. Lek M, Karczewski KJ, Minikel EV, et al. Analysis of protein-coding genetic variation in 60,706 humans. Nature. 2016;536(7616):285-91.

28. Bendl J, Stourac J, Salanda O, et al. Predict SNP: robust and accurate consensus classifier for prediction of disease related mutations. PLoS Comput Biol. 2014:10(1):e1003440.

29. Sucularli C, Arslantas M. Computational prediction and analysis of deleterious cancer associated missense mutations in DYNC1H1. Mol Cell Probes. 2017;34:21-9.

30. Cheng J, Randall A, Baldi P. Prediction of protein stability changes for singlesite mutations using support vector machines. Proteins. 2006;62(4):1125-32.

31. Capriotti E, Fariselli P, Casadio R. I-Mutant2.0: predicting stability changes upon mutation from the protein sequence or structure. Nucleic Acids Res. 2005;33(Web Server issue):W306-10.

32. Quan L, LV Q, Zhang Y. STRUM: structure-based prediction of protein stability changes upon single-point mutation. Bioinformatics. 2016;32(19): 2936-46.

33. Johansen C, Funding AT, Otkjaer K, et al. Protein expression of TNF-alpha in psoriatic skin is regulated at a post transcriptional level by MAPK-activated protein kinase 2. J Immunol. 2006;176:1431-8.

34. Raul U, Sawant S, Dange P, et al. Implications of cytokeratin 8/18 filament formation in stratified epithelial cells: induction of transformed phenotype Int J Cancer. 2004:111:662-8.

35. Meng L, Du J, Li W, et al. Study of a family with epidermolysis bullosa simplex resulting from a novel mutation of KRT14 gene. Zhonghua Yi Xue Yi Chuan Xue Za Zhi. 2017;34(4):504-8.

36. Wang WH, Zhang L, Li LF, et al. Ichthyosis hystrix Lambert type and CurthMacklin type are a single entity with affected (KRT1 mutation) or unaffected (KRT10 mutation) palms and soles? Eur J Dermatol. 2016;26(5):493-5.

37. Chen PJ, Li CX, Wen J, et al. S159P mutation of keratin 10 gene causes severe form of epidermolytic hyperkeratosis. J Eur Acad Dermatol Venereol. 2016;30(10):e102-4.

38. Dai L, Wu J, Guo H, et al. Mutation p.Leu128Pro in the 1A domain of K16 causes pachyonychia congenita with focal palmoplantar keratoderma in a Chinese family. Eur J Pediatr. 2014;173(6):737-41.

39. Jiang $M$, Sun Z, Dang $E$, et al. TGFß/SMAD/microRNA-486-3p signaling axis mediates keratin 17 expression and keratinocyte hyperproliferation in psoriasis. J Invest Dermatol. 2017;137(10):2177-86.

40. Segre JA. Epidermal barrier formation and recovery in skin disorders. J Clin Invest. 2006:116(5):1150-8.

41. Rugg EL, McLean WH, Lane EB, Pitera R, McMillan JR, Dopping-Hepenstal PJ, et al. A functional "knockout" of human keratin 14. Genes Dev. 1994:8(21): 2563-73.

42. Chan Y, Anton-Lamprecht I, Yu OC, Jäckel A, Zabel B, Ernst JP, et al. A human keratin 14 "knockout": the absence of K14 leads to severe epidermolysis bullosa simplex and a function for an intermediate filament protein. Genes Dev. 1994;8(21):2574-87.

43. Jonkman MF, Heeres K, Pas HH, van Luyn MJ, Elema JD, Corden LD, et al. Effects of keratin 14 ablation on the clinical and cellular phenotype in a kindred with recessive epidermolysis bullosa simplex. J Invest Dermatol. 1996:107(5):764-9.

44. Schuilenga-Hut PH, Vlies PV, Jonkman MF, Waanders E, Buys $\mathrm{CH}$, Scheffer $\mathrm{H}$. Mutation analysis of the entire keratin 5 and 14 genes in patients with epidermolysis bullosa simplex and identification of novel mutations. Hum Mutat 2003:21(4):447.

45. Homberg M, Ramms L, Schwarz N, Dreissen G, Leube RE, Merkel R, et al. Distinct impact of two keratin mutations causing epidermolysisbullosa simplex on keratinocyte adhesion and stiffness. J Invest Dermatol. 2015; 135(10):2437-45.

46. Szeverenyi I, Cassidy AJ, Chung CW, et al. The Human Intermediate Filament Database: comprehensive information on a gene family involved in many human diseases. Hum Mutat. 2008;29:351-60. 
47. D'Alessandro M, Russell D, Morley SM, et al. Keratin mutations of epidermolysis bullosa simplex alter the kinetics of stress response to osmotic shock. J Cell Sci. 2002;115:4341-51.

48. Russell $D$, Ross $H$, Lane EB. ERK involvement in resistance to apoptosis in keratinocytes with mutant keratin. J Invest Dermatol. 2010;130:671-81.

49. Syder AJ, Yu QC, Paller AS, et al. Genetic mutations in the K1 and K10 genes of patients with epidermolytic hyperkeratosis. Correlation between location and disease severity. J Clin Invest. 1994;93:1533-42.

50. McLean WH, Morley SM, Higgins C, et al. Novel and recurrent mutations in keratin 10 causing bullous congenital ichthyosiformerthroderma. Exp Dermatol. 1999;8:120-3.

51. Reichelt J, Magin TM. Hyperproliferation, induction of c-Myc and 14-3-30, but no cell fragility in keratin-10-null mice. J Cell Sci. 2002;115:2639-50.

52. Reichelt J, Furstenberger G, Magin TM. Loss of keratin 10 leads to mitogen-activated protein kinase (MAPK) activation, increased keratinocyte turnover, and decreased tumor formation in mice. J Invest Dermatol. 2004;123(5):973-81.

53. Ishidayamamoto A, lizuka $H$, Manabe $M$, et al. Altered distribution of keratinization markers in epidermolytic hyperkeratosis. Arch Dermatol Res. 1995;287:705-11.

54. Porter RM, Lane EB. Phenotypes, genotypes and their contribution to understanding keratin function. Trends Genet. 2003;19:278-85.

55. Cacoub P, Artru L, Canesi M, Koeger AC, Camus JP. Lifethreatening psoriasis relapse on withdrawal of cyclosporin. Lancet. 1988;2:219-20.

56. Georgala S, Koumantaki E, Rallis E, Papadavid E. Generalized pustular psoriasis developing during withdrawal of short-term cyclosporin therapy. Br J Dermatol. 2000;142:1057-8.

57. Fabiano A, De Simone C, Gisondi P, Piaserico S, Lasagni C, Pellacani G, et al. Management of patients with psoriasis treated with biological drugs needing a surgical treatment. Drug Dev Res. 2014;75(Suppl 1):S24-6.5.

58. Masson Regnault M, Konstantinou MP, Khemis A, Poulin Y, Bourcier M, Amelot $F$, et al. Early relapse of psoriasis after stopping brodalumab: a retrospective cohort study in 77 patients. J Eur Acad Dermatol Venereol. 2017;6 [Epub ahead of print]

59. McLean WH, Rugg EL, Lunny DP, et al. Keratin 16 and keratin 17 mutations cause pachyonychia congenita. Nat Genet. 1995;9:273-8

60. Connors JB, Rahil AK, Smith FJ, et al. Delayed-onset pachyonychia congenita associated with a novel mutation in the central $2 \mathrm{~B}$ domain of keratin $16 . \mathrm{Br}$ J Dermatol. 2001;144:1058-62.

61. Smith FJ, Corden LD, Rugg EL, et al. Missense mutations in keratin 17 cause either pachyonychia congenita type 2 or a phenotype resembling steatocystoma multiplex. J Invest Dermatol. 1997;108:220-3.

62. Smith FJ, Fisher MP, Healy E, et al. Novel keratin 16 mutations and protein expression studies in pachyonychia congenita type and focal palmoplantar keratoderma. Exp Dermatol. 2000;9:170-7.

63. Smith FJ. Nail that mutation-keratin 17 defect in late-onset pachyonychia. J Invest Dermatol. 2004;122:x-xi.

64. Lessard JC, Coulombe PA. Keratin 16-null mice develop palmoplantar keratoderma, a hallmark feature of pachyonychia congenita and related disorders. J Invest Dermatol. 2012;132(5):1384-91.

65. Paladini RD, Takahashi K, Bravo NS, Coulombe PA. Onset of reepithelialization after skin injury correlates with a reorganization of keratin filaments in wound edge keratinocytes: defining a potential role for keratin 16. J Cell Biol. 1996;132(3):381-97.

66. Kim S, Wong P, Coulombe PA. A keratin cytoskeletal protein regulates protein synthesis and epithelial cell growth. Nature. 2006;441:362-5.

67. Castelijns FA, Gerritsen MJ, van Vlijmen-Willems IM, et al. Proliferation is the main epidermal target in the treatment of psoriatic plaques with once daily application of tacalcitol ointment. Acta Derm Venereol. 1999; 79(2):111-4.

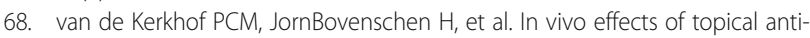
psoriatic treatments on cutaneous inflammation, epidermal proliferation and keratinisation. Current Drug Therapy. 2007;2:21-6.

69. de Jong EMG, Ferrier CM, de Zwart A, et al. Effects of topical treatment with budesonide on parameters for epidermal proliferation, keratinization and inflammation in psoriasis. J Dermatol Sci. 1995;9:185-94.

70. de Jong EM, van Vlijmen IM, van Erp PE, Ramaekers FC, Troyanovski SM, van de Kerkhof PC. Keratin 17: a useful marker in anti-psoriatic therapies. Arch Dermatol Res. 1991;283(7):480-2.

71. Fu M, Wang G. Keratin 17 as a therapeutic target for the treatment of psoriasis. J DermatolSci. 2012;67(3):161-5.
72. Bowden PE, Knight AG, Liovic M. A novel mutation (p.Thrl98Ser) in the $1 \mathrm{~A}$ helix of keratin 5 causes the localized variant of epidermolysis bullosa simplex. ExpDermatol. 2009;18(7):650-2.

73. Glasz-Bona A, Medvecz M, Sajo R, Lepesi-Benko R, Tulassay Z, Katona M, et al. Easy method for keratin 14 gene amplification to exclude pseudogene sequences: new keratin 5 and 14 mutations in epidermolysis bullosa simplex. J Invest Dermatol. 2009;129:229-31.

\section{Ready to submit your research? Choose BMC and benefit from:}

- fast, convenient online submission

- thorough peer review by experienced researchers in your field

- rapid publication on acceptance

- support for research data, including large and complex data types

- gold Open Access which fosters wider collaboration and increased citations

- maximum visibility for your research: over $100 \mathrm{M}$ website views per year

At BMC, research is always in progress.

Learn more biomedcentral.com/submissions 